Article

\title{
Antihyperglycemic Effects of Salvia polystachya Cav. and Its Terpenoids: $\alpha$-Glucosidase and SGLT1 Inhibitors
}

\author{
Rocio Ortega ${ }^{1,2,3, *} \mathbb{C}$, Miguel Valdés $3, * \mathbb{C}$, Francisco J. Alarcón-Aguilar ${ }^{4}$, Ángeles Fortis-Barrera ${ }^{4}$, \\ Elizabeth Barbosa ${ }^{5}$, Claudia Velazquez ${ }^{6}$ and Fernando Calzada ${ }^{3, *} \mathbb{C}$
}

1 Doctorado en Ciencias Biológicas y de la Salud, Universidad Autónoma Metropolitana-Iztapalapa, UAM-I, Mexico City CP 09340, Mexico

2 Av. San Rafael Atlixco 186, Leyes de Reforma 1ra Sección, Mexico City CP 09340, Mexico

3 Unidad de Investigación Médica en Farmacología, UMAE Hospital de Especialidades, $2^{\circ}$ Piso CORSE Centro Médico Nacional Siglo XXI, IMSS, Av. Cuauhtémoc 330, Col. Doctores, Mexico City CP 06725, Mexico

4 Laboratorio de Farmacología, Departamento de Ciencias de la Salud, División de CBS, Universidad Autónoma Metropolitana-Iztapalapa, UAM-I, Av. San Rafael Atlixco 186, Leyes de Reforma 1ra Sección, Mexico City CP 09340, Mexico; aaaf@xanum.uam.mx (F.J.A.-A.); fortis11_10@yahoo.com.mx (Á.F.-B.)

5 Escuela Superior de Medicina, Instituto Politécnico Nacional, Salvador Díaz Mirón esq. Plan de San Luis S/N, Miguel Hidalgo, Casco de Santo Tomas, Mexico City CP 11340, Mexico; rebc78@yahoo.com.mx

6 Área Académica de Farmacia, Instituto de Ciencias de la Salud, Universidad Autónoma del Estado de Hidalgo, Km 4.5, Carretera Pachuca-Tulancingo, Unidad Universitaria, Pachuca CP 42076, Mexico; cvg09@yahoo.com

* Correspondence: rciortega@hotmail.com (R.O.); valdesguevaramiguel@gmail.com (M.V.); fernando.calzada@imss.gob.mx or fercalber10@gmail.com (F.C.); Tel.: +52-1-55-5627-6900 (ext. 21367) (R.O. \& M.V. \& F.C.)

\section{check for} updates

Citation: Ortega, R.; Valdés, M.; Alarcón-Aguilar, F.J.; FortisBarrera, Á.; Barbosa, E.; Velazquez, C.; Calzada, F. Antihyperglycemic Effects of Salvia polystachya Cav. and Its Terpenoids: $\alpha$-Glucosidase and SGLT1 Inhibitors. Plants 2022, 11, 575. https:// doi.org/10.3390/plants11050575

Academic Editors: Stephen O. Amoo and Vanessa Steenkamp

Received: 5 January 2022

Accepted: 17 February 2022

Published: 22 February 2022

Publisher's Note: MDPI stays neutral with regard to jurisdictional claims in published maps and institutional affiliations.

Copyright: (C) 2022 by the authors. Licensee MDPI, Basel, Switzerland. This article is an open access article distributed under the terms and conditions of the Creative Commons Attribution (CC BY) license (https:// creativecommons.org/licenses/by/ $4.0 /)$.

\begin{abstract}
The antihyperglycemic activity of ethanolic extract from Salvia polystachya (EESpS) and its products was evaluated using in vivo, ex vivo and in silico assays; additionally, an acute toxicity assay was evaluated. EESpS was classified as a nontoxic class 5 drug. EESpS, ethyl acetate fraction (EtOAcFr), secondary-6-fraction (SeFr6), ursolic acid (UA), and oleanolic acid (OA) reduced the hyperglycemia in DM2 mice. $\alpha$-glucosidase inhibition was evaluated with oral sucrose and starch tolerance tests (OSuTT and OStTT), an intestinal sucrose hydrolysis (ISH) assay and molecular docking studies using acarbose as control. SGLT1 inhibition was evaluated with oral glucose and galactose tolerance tests (OGTT and OGaTT), an intestinal glucose absorption (IGA) assay and molecular docking studies using canagliflozin as the control. During the carbohydrate tolerance tests, all the treatments reduced the postprandial peak, similar to the control drugs. During the ISH, IC $_{50}$ values of 739.9 and $726.3 \mu \mathrm{M}$ for UA and OA, respectively, were calculated. During the IGA, IC 50 values of 966.6 and 849.3 for UA, OA respectively, were calculated. Finally, during the molecular docking studies, UA and OA showed $\Delta \mathrm{G}$ values of -6.41 and $-5.48 \mathrm{kcal} / \mathrm{mol}^{-1}$, respectively, on $\alpha$-glucosidase enzymes. During SGLT1, UA and OA showed $\Delta \mathrm{G}$ values of -10.55 and -9.65 , respectively.
\end{abstract}

Keywords: Salvia polystachya; antihyperglycemic activity; $\alpha$-glucosidase inhibitor; SGLT1 inhibitor; acute oral toxicity; docking analysis; ursolic acid; oleanolic acid; diabetes mellitus

\section{Introduction}

Diabetes mellitus (DM) is a serious chronic disease that occurs when there is no optimal use of insulin in the organism due to a lack of insulin production or because the organism cannot properly use the insulin that is produced due to insulin resistance [1,2]. This alteration in insulin production and utilization is reflected in an increase in the concentration of blood glucose, known as hyperglycemia [3]. There are several drug families that are used as a treatment for DM, and all drug families are classified according to their mechanism pathway. Drugs classified as secretagogues include sulfonylureas and meglitinides [4], 
insulin sensitizers include biguanides and thiazolidinediones [5], and other drugs include glucagon-like peptide 1 (GLP-1) analogues [6], dipeptidyl peptidase-4 (DPP4) inhibitors [7], $\alpha$-glucosidase [8,9], and SGLT inhibitors [10]. However, despite the therapeutic effect that is wanted after the administration of the treatments previously described, all of them have side effects such as hypoglycemia, gastrointestinal disorders, diarrhea, nausea, vomiting, abdominal discomfort, flatulence production, and urinary tract infection, among others [11]. One of the principal approaches for reducing postprandial hyperglycemia in the type 2 diabetes (T2D) population is the prevention of hydrolysis and the absorption of carbohydrates after food uptake. Therefore, the effective reduction of blood glucose levels after food uptake can be a key step in preventing or reversing diabetic complications and improving the life quality of T2D patients [12]. This reduction of hydrolysis and the absorption of carbohydrates can be reached with the inhibition of $\alpha$-glucosidase and sodium-glucose cotransporter type 1 (SGLT1) enzymes [13]. In the first case, the $\alpha$-glucosidase enzymes are located in the small bowel brush, and they degrade oligosaccharides such as sucrose and lactose to monosaccharides such as $\alpha$-glucose by hydrolyzing the glycosidic bonds [14], delaying the absorption of carbohydrates since complex carbohydrates cannot be absorbed; thus, postprandial hyperglycemia can be delayed [14]. SGLT1 is highly expressed on the brush border membrane of enterocytes in the proximal part of the small intestine. It is responsible for glucose absorption. SGLT1 enzymes couple with the entrance of $\mathrm{Na}+$ and glucose, facilitating the transport of glucose from the small intestine into the enterocyte; subsequently, the accumulated glucose in the enterocytes is mobilized out of them by glucose transport facilitating systems (GLUTs), and absorbed into the bloodstream [15]. Accordingly, both mechanisms of action are important points to take into account in the search for new molecules that help to reduce hyperglycemia in T2D patients.

One alternative which a major part of the population adopts is the use of medicinal plants; some of them are used for the treatment of several disorders and represent a potential source of valuable drugs in several pathologies, including T2D [16], a disease with the highest rates of prevalence and mortality worldwide [17,18]. Globally, the population uses medicinal plants to treat diabetes symptoms in an empirical way [19]. In this sense, several species of the Lamiaceae family have been proposed as $\alpha$-glucosidase inhibitors, including S. amarissima, S. urmiensis, S. miltiorrhiza, S. splendens, S. hypoleuca, S. fruticosa, S. syriaca, S. santolinifolia, S. moorcraftiana, S. limbata, S. atropatana, S. nemorosa, and S. multicaulis [20-24]. Moreover, the diterpenes amarisolide, teotihuacanin, and amarissinins $A$ and $C$ are reported as the active principles in S. amarissima $[25,26]$. Moreover, in S. reptans, S. microphylla and S. amarissima, the presence of ursolic acid (UA), oleanolic acid (OA) and $\beta$-sitosterol [27-29] has been reported, which have shown significant inhibitory activity towards $\alpha$-glucosidase [29].

The interest in the study of terpenes has increased because several authors have reported this kind of compound to have multiple biological attributes that can be useful for the treatment of several diseases; these biological attributes include antifungal, antibacterial, antiviral, antitumor, antiparasitic, anti-inflammatory, analgesic and hypoglycemic properties [30]. Considering the above, Salvia polystachya Cav. (Lamiaceae) is a herbaceous and perennial plant endemic to Mexico, known as "chía" [31,32]. It has been reported to have several properties, such as purgative, antipyretic, antimalarial, antihemorrhagic, and emollient effects, as well as having been reported as an effective treatment for heartburn and dysentery $[33,34]$. From the leaves, neo-clerodane diterpenes, such as polystachynes A-H, 15-epi-polystachine $\mathrm{G}$, salvifiline A and C, 15-epi-salvifiline A, and linearolactone, and the flavone 3',5,6,7-tetrahydroxy-4'-methoxyflavone, were isolated [33,34]. Among these, the diterpene linearolactone exhibited antiprotozoal activity in Entamoeba histolytica and Giardia lamblia [35]; moreover, polystachynes B and G, linearolactone and 15-epi-salvifiline A increased the gene expression of elastin and the type I, III, and V of collagens [36]. Although several species of the Salvia genus have been reported to have antidiabetic properties, there are no scientific reports that support $S$. polystachya's effects on hyperglycemia yet. Thus, considering the chemotaxonomical criteria, the aim of our study was to explore the 
potential antidiabetic effect of $S$. polystachya and its isolated products, as well to evaluate its effect as an $\alpha$-glucosidase and SGLT1 inhibitor using activity-guided fractionation as a strategy, using in vivo, ex vivo and in silico assays.

\section{Results}

\subsection{In Vivo Assays}

\subsubsection{Acute Oral Toxicity of the Ethanolic Extract of the Stems from S. polystachya}

Acute oral toxicity assays of the extract from S. polystachya stems were performed according to Guideline 423 of the OECD [37]. It was found that $4 \mathrm{~h}$ after the administration of the treatments, the extract did not generate alterations in the animals. Moreover, EESpS did not generate mortality at the doses evaluated. At the end of the test (14 days), the surviving mice did not display body weight loss compared with normal mice (Table 1).

Table 1. Effect of the acute administration of ethanolic extract of the stems obtained from S. polystachya on the body weight and relative organ weight of normal female mice.

\begin{tabular}{cccccc}
\hline Group & Dose $\mathbf{( m g / k g )}$ & Pancreas $\mathbf{( g )}$ & Liver $(\mathbf{g})$ & Kidneys $(\mathrm{g})$ & Stomach $(\mathrm{g})$ \\
\hline \multirow{2}{*}{ Normal } & - & $0.8 \pm 0.0$ & $4.9 \pm 0.1$ & $1.2 \pm 0.05$ & $1.4 \pm 0.1$ \\
& 50 & $0.7 \pm 0.0$ & $4.5 \pm 0.2$ & $1.1 \pm 0.1$ & $2.1 \pm 0.1$ \\
EESpS & 300 & $0.6 \pm 0.1$ & $5.0 \pm 0.3$ & $1.2 \pm 0.1$ & $2.0 \pm 0.5$ \\
& 2000 & $0.8 \pm 0.2$ & $4.8 \pm 0.2$ & $1.2 \pm 0.0$ & $1.9 \pm 0.5$ \\
\hline
\end{tabular}

Mean \pm SEM of relative organ weight (g) of normal female mice $(n=3)$. (ANOVA followed by Dunnett post hoc test) vs. the normal group values. EESpS: ethanolic extract of the stem.

2.1.2. Acute Effect of Ethanolic Extract of Stems from S. polystachya and its Products over Glycemia in Normal and Diabetic Mice

Considering that EESpS did not show toxicity, the acute evaluation in diabetic mice was carried out. The doses selected were 50,100 , and $200 \mathrm{mg} / \mathrm{kg}^{-1}$. The results showed that the dose with the best effect on hyperglycemia was $100 \mathrm{mg} / \mathrm{kg}^{-1}$. This effect was similar to that observed in the groups treated with the control drugs acarbose and glibenclamide (Table 2). Acarbose, an $\alpha$-glucosidase inhibitor, was used as the comparative control. In the case of glibenclamide, it was used to demonstrate pancreatic $\beta$-cell viability in streptozocin-induced diabetic mice in agreement with the T2D model.

Table 2. Acute effect of the ethanolic extract of stems from S. polystachya and its products over glycemia.

\begin{tabular}{|c|c|c|c|c|c|c|}
\hline Group & Dose $\left(\mathrm{mg} / \mathrm{kg}^{-1}\right)$ & $0 \mathrm{~min}$ & $30 \mathrm{~min}$ & $60 \mathrm{~min}$ & $90 \mathrm{~min}$ & $120 \mathrm{~min}$ \\
\hline NM control & - & $175.3 \pm 1.4$ & $174 \pm 1.8$ & $170.5 \pm 2.6$ & $172.8 \pm 2$ & $178.5 \pm 1.7$ \\
\hline DM control & - & $302.5 \pm 5.7$ & $306 \pm 3.7$ & $309.4 \pm 2.8$ & $311.5 \pm 1.5$ & $294.8 \pm 0.6$ \\
\hline $\mathrm{DM}+\mathrm{EESpS}$ & 50 & $295.5 \pm 5$ & $310.3 \pm 12$ & $290.3 \pm 14$ & $300 \pm 20$ & $291.8 \pm 1$ \\
\hline $\mathrm{DM}+\mathrm{EESpS}$ & 100 & $301.8 \pm 1$ & $242.3 \pm 0.6 *$ & $258.3 \pm 1.2^{* *}$ & $241.3 \pm 0.8$ & $247.3 \pm 0.3$ \\
\hline $\mathrm{DM}+\mathrm{EESpS}$ & 200 & $303.3 \pm 10$ & $320.4 \pm 7.3$ & $307.8 \pm 1.3$ & $287 \pm 9.5^{\square}$ & $313.3 \pm 3.5$ \\
\hline $\mathrm{DM}+\mathrm{AqRFr}$ & 50 & $309 \pm 2.6$ & $268.4 \pm 2.7$ & $231.6 \pm 3.4$ & $218.8 \pm 1$ & $213.3 \pm 7.9$ \\
\hline $\mathrm{DM}+\mathrm{EtOAcFr}$ & 50 & $300 \pm 4.8$ & $249 \pm 5.9 *$ & $203.3 \pm 1.8^{* *}$ & $213 \pm 4.4$ & $187.5 \pm 0.6$ \\
\hline $\mathrm{DM}+$ SeFr6 & 50 & $293.5 \pm 2.5$ & $338.8 \pm 2.2$ & $386 \pm 3.9$ & $330.3 \pm 4.2$ & $259.3 \pm 5.1$ \\
\hline DM + Oleanolic acid & 50 & $283.2 \pm 5.2$ & $302 \pm 11.4$ & $302 \pm 7.2$ & $239.4 \pm 3.1$ & $252.8 \pm 2.9$ \\
\hline DM + Ursolic acid & 50 & $268.7 \pm 4$ & $220.8 \pm 5.9 *$ & $239 \pm 6.6^{* *}$ & $259.2 \pm 4$ & $236 \pm 5.5$ \\
\hline $\mathrm{DM}+$ Acarbose & 50 & $308.7 \pm 1.6$ & $236.8 \pm 2.3 *$ & $237.8 \pm 3.4^{* *}$ & $249 \pm 1.5^{\square}$ & $225 \pm 2.5$ \\
\hline DM + Glibenclamide & 50 & $307.6 \pm 1.8$ & $243.5 \pm 6.2 *$ & $247.8 \pm 5.4^{* *}$ & $268 \pm 1.9$ & $292 \pm 2.3$ \\
\hline
\end{tabular}

Blood glucose levels, mean $\pm \operatorname{SEM}(n=6){ }^{*} p>0.05$ significantly different vs. DM control 30 min; ${ }^{* *} p>0.05$ significantly different vs. DM control $60 \mathrm{~min} ; p>0.05$ significantly different vs. DM control 90 min; $p>0.05$ significantly different vs. DM control $120 \mathrm{~min}$ (ANOVA followed by Dunnett post hoc test). GLIB: glibenclamide; ACAR: acarbose; EESpS: ethanolic extract of the stem from S. polystachya.

Once its activity over hyperglycemia was demonstrated, EESpS was subjected to partition, obtaining two fractions, AqRFr and EtOAcFr, which were also evaluated in diabetic mice (Table 2). Both fractions significantly reduced blood glucose from 30 to 
$120 \mathrm{~min}$; this activity was similar to that of the control drug, acarbose. Nevertheless, EtOAcFr was selected to continue the study because its effect on hyperglycemia was slightly greater compared with the observed effect in AqRFr.

EtOAcFr was subjected to secondary fractionation using column chromatography; ten secondary fractions (SeFr1-SeFr10) were obtained, and they were evaluated in diabetic mice. The secondary fraction SeFr6 was the only one with a significant effect on the hyperglycemic values at $120 \mathrm{~min}$ (Table 2). SeFr6 was compared with 42 standard compounds of different polarities including polystachynes $\mathrm{A}, \mathrm{B}$, and $\mathrm{D}$, as well as linearolactone, which was previously isolated from S. polystachya [35]. The analysis of SeFr6 was performed using high-performance liquid chromatography with diode array detection (HPLC-DAD), and the standards of the ursolic acid and oleanolic acid were used. Figure 1 shows the HPLC chromatograms of EtOAcFr, SeFr6, UA and OA. The complete analysis of the chromatogram of SeFr6 (Figure 1a) showed the presence of UA at $8.008 \mathrm{~min}(17.26 \%)$ and OA at $8.366 \mathrm{~min}(47.28 \%)$; these were compared with the chromatograms of UA and OA standards (Figure $1 \mathrm{c}$ and 1d, respectively).

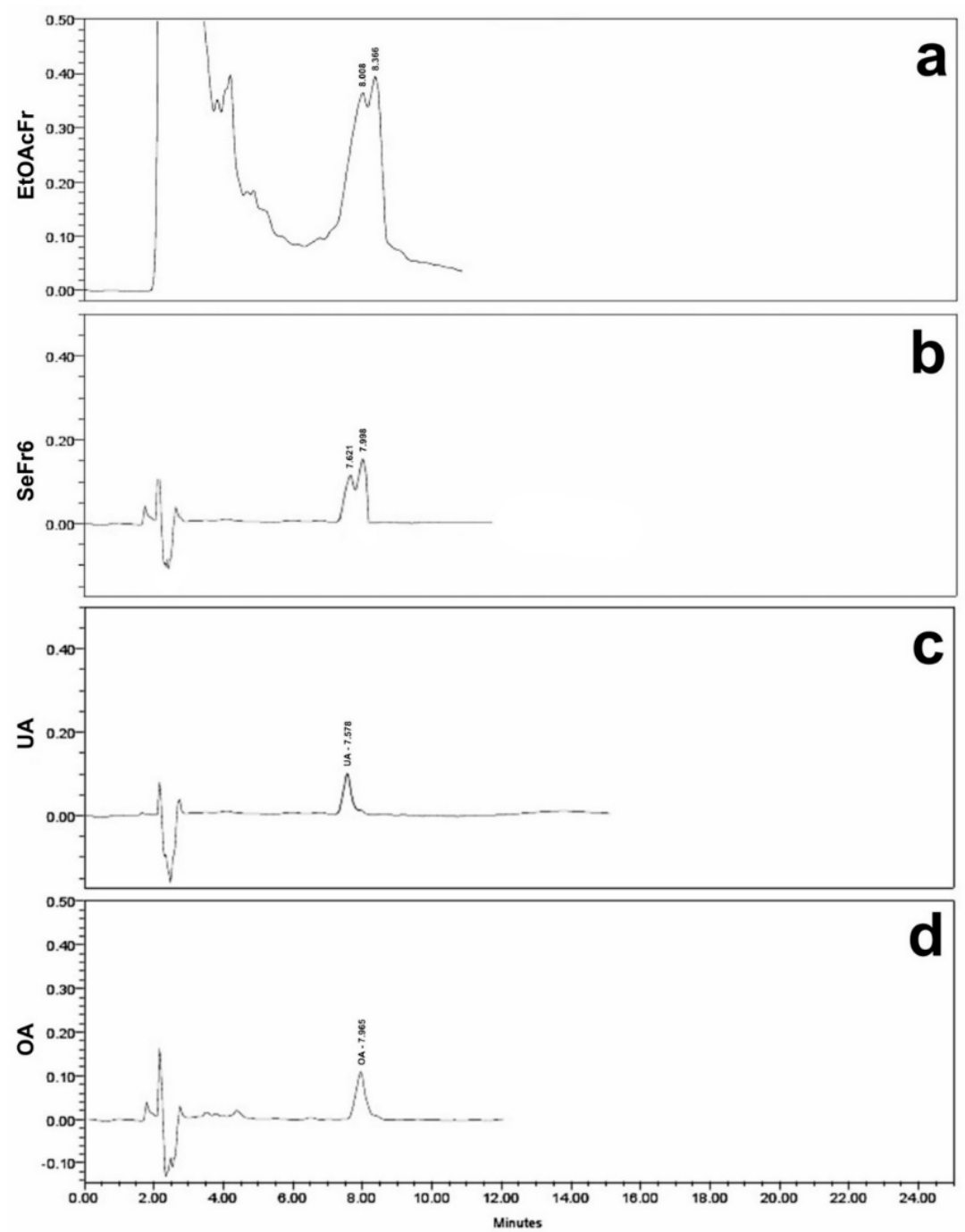

Figure 1. HPLC-DAD chromatograms of EtOAcFr (a), SeFr6 (b), UA (c) and OA (d) standard.

The compounds identified, UA and OA, were evaluated in diabetic mice (Table 2). OA significantly decreased the blood glucose levels after $90 \mathrm{~min}$, until $120 \mathrm{~min}$. In the case of UA, this compound significantly decreased blood glucose levels after $30 \mathrm{~min}$, until $120 \mathrm{~min}$; this effect was similar to glibenclamide. 
2.1.3. Oral Sucrose and Starch Tolerance Tests of the Products Obtained from Stems from S. polystachya

During the OSuTT assay, all the treatments reduced the postprandial glucose peak. It is important to mention that EESpS, EtOAcFr (Figure 2A), OA, and UA (Figure 2B) significantly reduced the hyperglycemia peak observed $30 \mathrm{~min}$ after the sucrose load, with percentages of the inhibition of the peak of 30.6, 47.8, 29.8 and 30.7\%, respectively. The activity demonstrated by the products obtained from the stems of S. polystachya was less than the activity observed after the administration of the control drug acarbose, an $\alpha$-glucosidase inhibitor, which significantly reduced the postprandial peak with $100 \%$ inhibition at $30 \mathrm{~min}$.

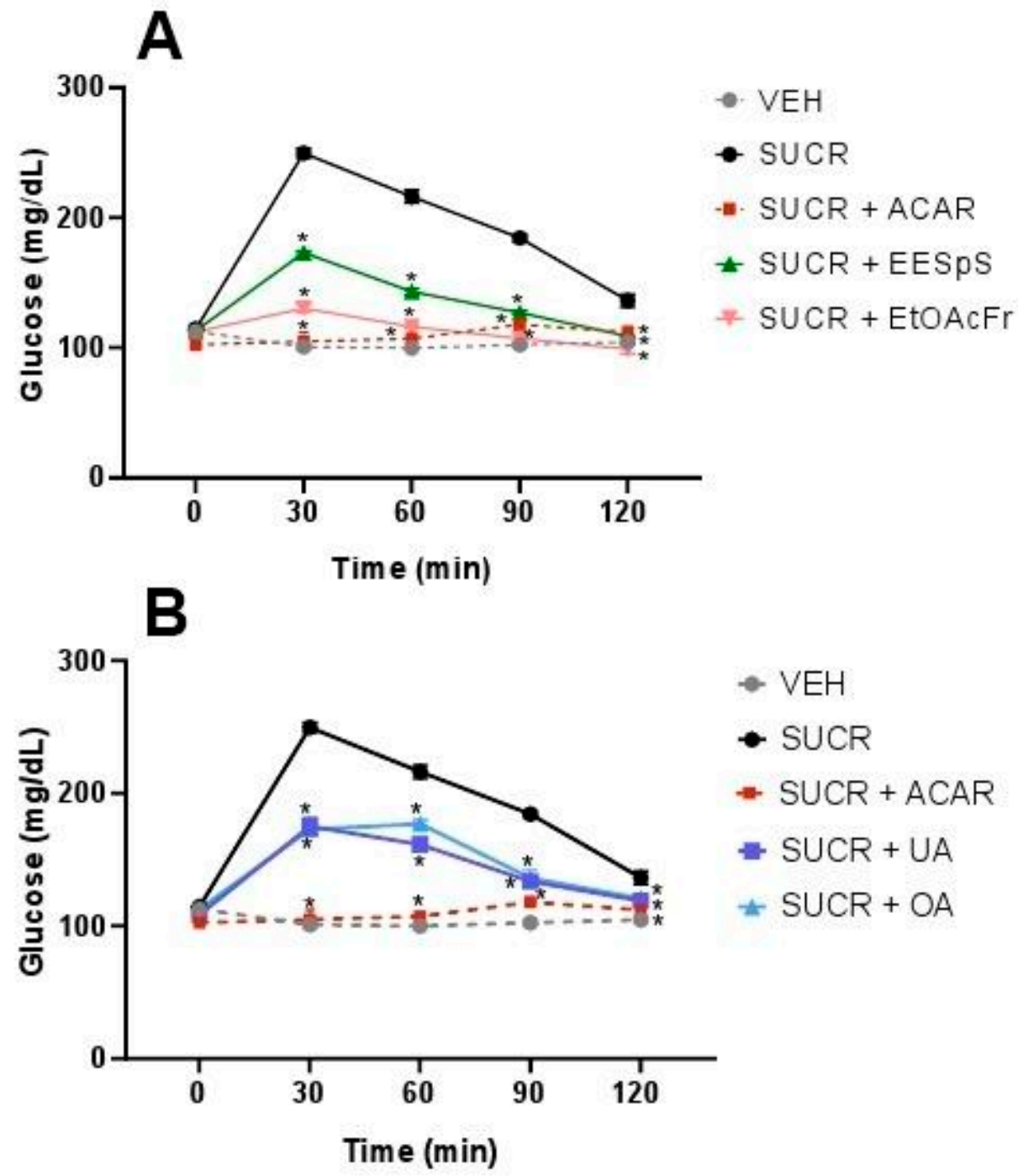

Figure 2. Effect of products obtained from the stems from S. polystachya in oral sucrose tolerance test (OSuTT). (A) OSuTT of groups treated with sucrose, acarbose, EESpS and EtOAcFr, as well as vehicle. (B) OSuTT of groups treated with sucrose, acarbose, UA and OA, as well as vehicle. Results shown as mean $\pm \operatorname{SEM}(n=6)$. ${ }^{*} p>0.05$ significantly different vs. sucrose group values at the same time. (Two-way ANOVA followed by Dunnett post hoc test) ACAR: acarbose; SUCR: sucrose; EESpS: ethanolic extract of stem; EtOAcFr: ethyl acetate fraction; UA: ursolic acid and OA: oleanolic acid.

In OStTT, a similar effect to OSuTT was observed. EESpS significantly reduced the postprandial peak during the assay with a $32.9 \%$ reduction at $30 \mathrm{~min}$. In the case of EtOAcFr, there was only a significant reduction at $30 \mathrm{~min}$ with a $13.6 \%$ reduction (Figure $3 \mathrm{~A}$ ), in comparison with the starch group. When UA and OA were administered, a significant 
reduction in the postprandial peak was observed during all the assays with a 32.6 and $36 \%$ reduction at $30 \mathrm{~min}$, respectively. The control drug, acarbose, also reduced the postprandial peak, with a $25.9 \%$ reduction at $30 \mathrm{~min}$. It is important to mention that UA and OA showed a greater inhibitory effect than the control drug at $30 \mathrm{~min}$ (Figure $3 \mathrm{~B}$ ).

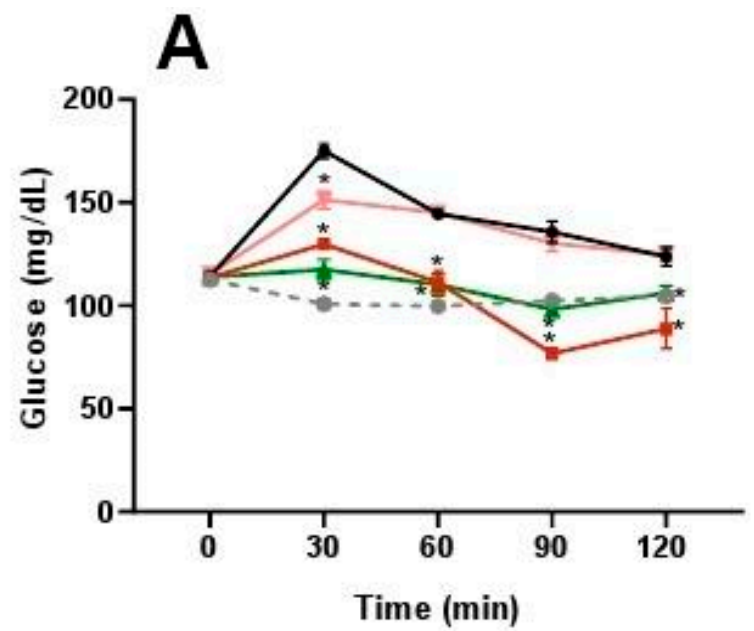

$$
\begin{aligned}
& \text { - VEH } \\
& \text { - STAR } \\
& \text { - STAR + ACAR } \\
& \text { - STAR + EESpS } \\
& \text { * STAR + EtOAcFr }
\end{aligned}
$$

B

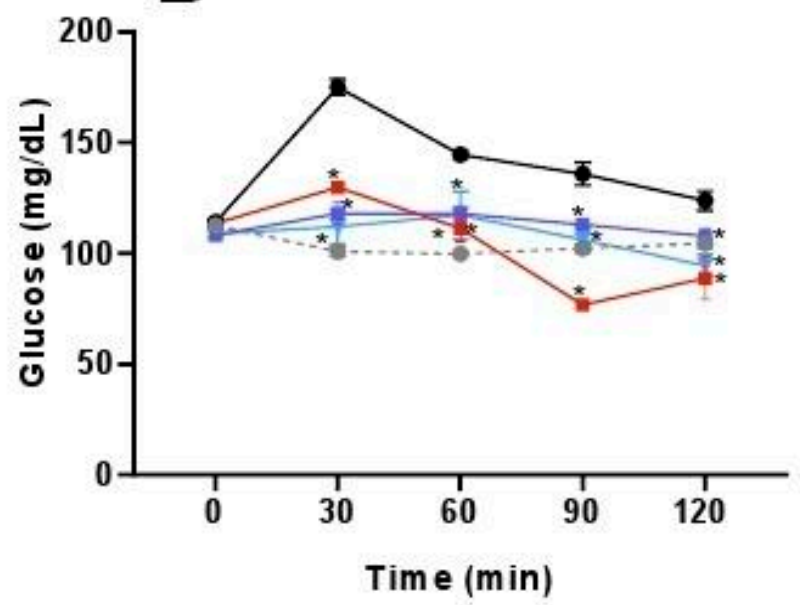

$\rightarrow$ VEH

- star

- STAR + ACA

- STAR + UA

* STAR + OA

Figure 3. Effect of products obtained from the stems from S. polystachya in oral starch tolerance test (OStTT). (A) OStTT of groups treated with starch, acarbose, EESpS and EtOAcFr, as well as vehicle. (B) OStTT of groups treated with starch, acarbose, UA and OA, as well as vehicle. Results shown as mean \pm SEM $(n=6) .{ }^{*} p>0.05$ significantly different vs. starch group values at the same time. (Two-way ANOVA followed by Dunnett post hoc test) ACAR: acarbose; STAR: starch; EESpS: ethanolic extract of stem; EtOAcFr: ethyl acetate fraction; UA: ursolic acid and OA: oleanolic acid.

2.1.4. Oral Glucose and Galactose Tolerance Tests of the Products Obtained from Stems from $S$. polystachya

EESpS, EtOAcFr, UA and OA were evaluated in oral glucose (OGTT) and galactose (OGaTT) tolerance tests, using canagliflozin, an inhibitor of SGLT1/2 cotransporters, as a control drug. EESpS and EtOAcFr significantly reduced the glucose postprandial peak at $30 \mathrm{~min}$. Their effect was similar to what was observed in the control drug canagliflozin (Figure 4A). When UA and OA were tested in OGTT, a significant reduction in the postprandial peak at $30 \mathrm{~min}$ in comparison with the glucose group was observed. However, this effect was lower than what was observed after the administration of canagliflozin (Figure 4B). 


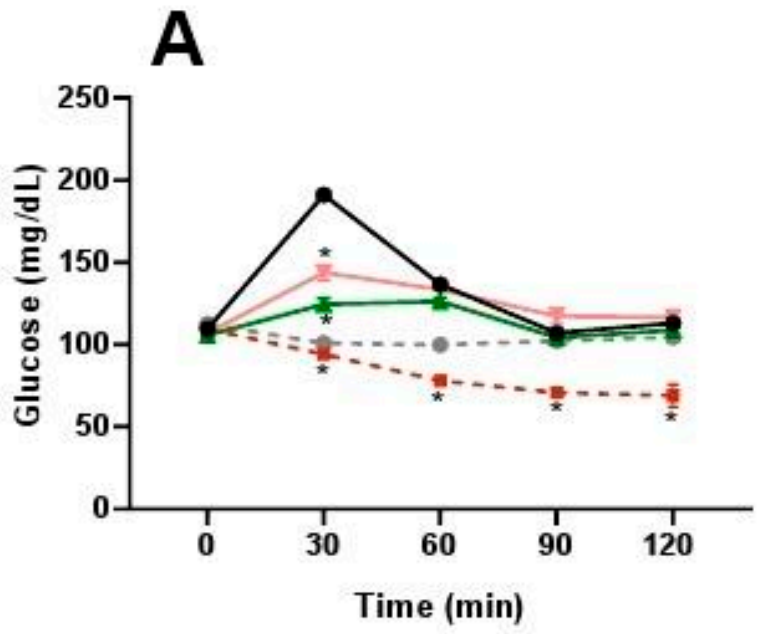

- VEH

- GluC

- glUC + CANA

$\star$ GLUC + EESpS

* GLUC + EtOAcFr

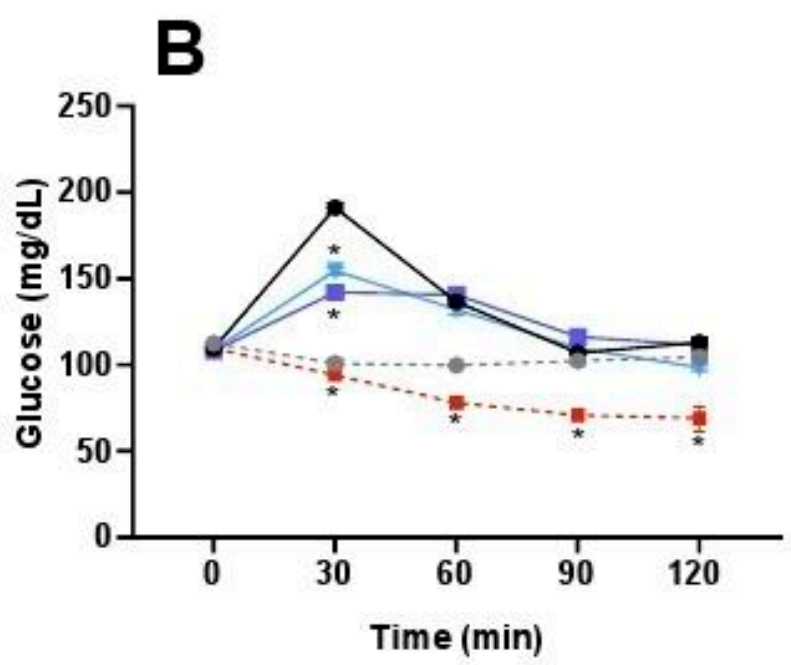

- VEH

- GLUC

- GLUC + CANA

- GLUC + UA

* GLUC + OA

Figure 4. Effect of products obtained from the stems from S. polystachya in oral glucose tolerance test (OGTT). (A) OGTT of groups treated with glucose, acarbose, EESpS and EtOAcFr, as well as vehicle. (B) OGTT of groups treated with glucose, acarbose, UA and OA, as well as vehicle. Results shown as mean $\pm \operatorname{SEM}(n=6) .{ }^{*} p>0.05$ significantly different vs. glucose group values at the same time. (Two-way ANOVA followed by Dunnett post hoc test) ACAR: acarbose; GLUC: glucose; EESpS: ethanolic extract of stem; EtOAcFr: ethyl acetate fraction; UA: ursolic acid and OA: oleanolic acid.

When the OGaTT was performed, the group treated with this carbohydrate showed a postprandial peak from $30 \mathrm{~min}$ and until the end of assay. The groups treated with EESpS and EtOAcFr showed a significant reduction in the postprandial peak from $60 \mathrm{~min}$ until the end of the assay (Figure 5A). Additionally, UA and OA significantly reduced the postprandial peak from 60 min until the end of the assay (Figure 5B). In all the treatments, the effects observed were less than the group treated with canagliflozin.

Once evaluated, the products in the in vivo assays were evaluated in ex vivo assays in order to determine if the antidiabetic activity was related to a reduction in intestinal sucrose hydrolysis as well as intestinal glucose absorption.

\subsection{Ex Vivo Assays}

2.2.1. Inhibition of Intestinal Sucrose Hydrolysis of the Products Obtained from the Stems from S. polystachya

After the addition of the treatments in the intestine portions, the EESpS, EtOAcFr and UA showed a significant reduction in the glucose absorbed at concentrations of 200, 400 and $800 \mu \mathrm{gmL}^{-1}$ with half-maximal inhibitory concentration $\left(\mathrm{IC}_{50}\right)$ calculated at 734.3 , $573.5 \mu \mathrm{gmL}^{-1}$, and $739.9 \mu \mathrm{M}$, respectively. When OA was evaluated, it showed a significant 
reduction in glucose absorbed at 400 and $800 \mu \mathrm{M}$ with an $\mathrm{IC}_{50}$ of $726.3 \mu \mathrm{M}$. Finally, acarbose showed a significant reduction in glucose absorbed at 200, 400 and $800 \mu \mathrm{M}$, and the $\mathrm{IC}_{50}$ calculated was $173 \mu \mathrm{M}$ (Table 3).

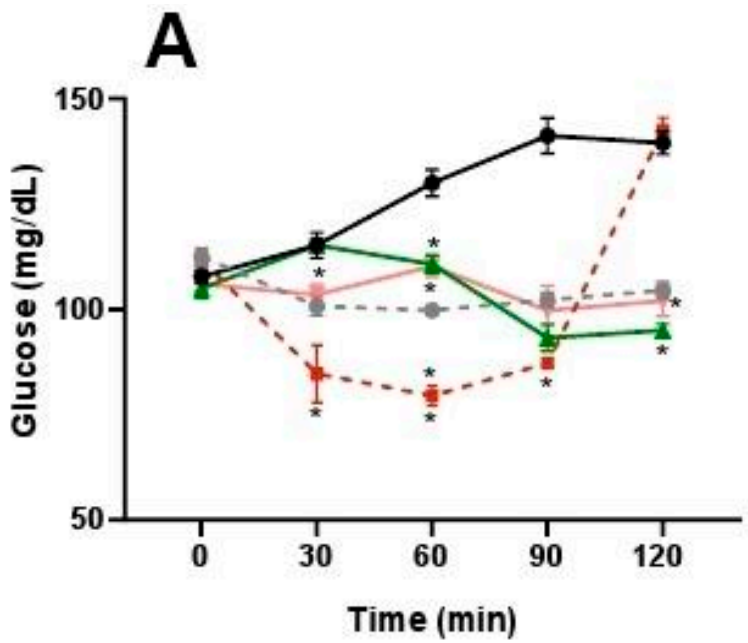

- VEH

- GALT

- GALT + CANA

GALT + EESpS

GALT + EtOAcFr
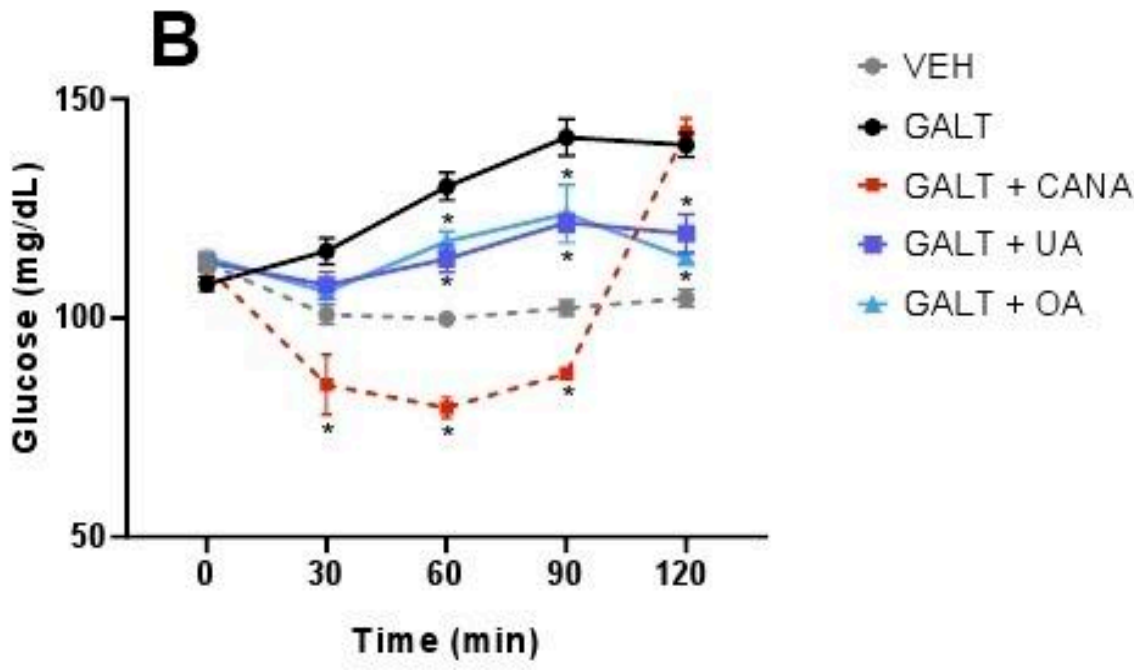

Figure 5. Effect of products obtained from the stems from S. polystachya in oral glucose tolerance test (OGaTT). (A) OGaTT of groups treated with galactose, acarbose, EESpS and EtOAcFr, as well as vehicle. (B) OGaTT of groups treated with galactose, acarbose, UA and OA, as well as vehicle. Results shown as mean $\pm \operatorname{SEM}(n=6) .{ }^{*} p>0.05$ significantly different vs. galactose group values at the same time. (Two-way ANOVA followed by Dunnett post hoc test) ACAR: acarbose; GALT: galactose; EESpS: ethanolic extract of stem; EtOAcFr: ethyl acetate fraction; UA: ursolic acid and OA: oleanolic acid.

2.2.2. Inhibition of Intestinal Glucose Absorption of the Products Obtained from the Stems from $S$. polystachya

When the treatments were added to the intestine portions in IGA, the EEsPS significantly reduced the quantity of glucose absorbed at 400 and $800 \mu \mathrm{gmL}^{-1}$ with a calculated $\mathrm{IC}_{50}$ of $1536.3 \mu \mathrm{gmL}^{-1}$. In the case of EtOAcFr, it showed a significant reduction in the glucose absorbed at concentrations of 200,400 and $800 \mu \mathrm{gmL}^{-1}$ with a calculated $\mathrm{IC}_{50}$ of $697.3 \mu \mathrm{gmL}^{-1}$. In the case of ursolic acid, it showed a significant reduction in glucose absorbed at 400 and $800 \mu \mathrm{M}$ with an $\mathrm{IC}_{50}$ of $966.6 \mu \mathrm{M}$. The oleanolic acid showed a significant reduction in glucose absorbed at 200, 400 and $800 \mu \mathrm{M}$, and the $\mathrm{IC}_{50}$ values calculated were 849.3 and $834.5 \mu \mathrm{M}$, respectively. Finally, canagliflozin showed a significative reduction in glucose absorbed at 400 and $800 \mu \mathrm{M}$, with a calculated $\mathrm{IC}_{50}$ of $834.5 \mu \mathrm{M}$ (Table 4 ). 
Table 3. Quantity of glucose measured in the external aqueous medium, percent inhibition, and $\mathrm{CE}_{50}$ calculated after addition of treatments on intestinal sucrose hydrolysis (ISH) inhibition test.

\begin{tabular}{|c|c|c|c|c|}
\hline Treatment & $\begin{array}{c}\text { Glucose } \\
\left(\mathrm{mg} / \mathrm{dL}^{-1}\right) \\
0 \mathrm{~h}\end{array}$ & Glucose $\left(\mathrm{mg} / \mathrm{dL}^{-1}\right)$ & $\%$ of Inhibition & $\mathrm{IC}_{50}$ \\
\hline Sucrose $(15 \%)$ & $0 \pm 0$ & $90.6 \pm 5.8$ & - & - \\
\hline EESpS $\left[200 \mu \mathrm{gmL}^{-1}\right]$ & $0 \pm 0$ & $71.6 \pm 1.6^{*}$ & $20.8 \pm 1.8$ & \\
\hline EESpS $\left[400 \mu \mathrm{gmL}^{-1}\right]$ & $0 \pm 0$ & $55 \pm 2 *$ & $39.2 \pm 2.2$ & $734.3 \mu \mathrm{gmL}^{-1}$ \\
\hline EESpS $\left[800 \mu \mathrm{gmL}^{-1}\right]$ & $0 \pm 0$ & $44 \pm 1.8^{*}$ & $51.4 \pm 2$ & \\
\hline EtOAcFr [200 $\left.\mu \mathrm{gmL}^{-1}\right]$ & $0 \pm 0$ & $65.6 \pm 1.2 *$ & $27.5 \pm 1.3$ & \\
\hline EtOAcFr $\left[400 \mu \mathrm{gmL}^{-1}\right]$ & $0 \pm 0$ & $51 \pm 1.4 *$ & $43.7 \pm 1.6$ & $573.5 \mu \mathrm{gmL}^{-1}$ \\
\hline EtOAcFr $\left[800 \mu \mathrm{g} / \mathrm{mL}^{-1}\right]$ & $0 \pm 0$ & $35 \pm 1.7 *$ & $61.3 \pm 1.8$ & \\
\hline UA $[200 \mu \mathrm{M}]$ & $0 \pm 0$ & $59.3 \pm 1.8 *$ & $34.5 \pm 2$ & \\
\hline UA $[400 \mu \mathrm{M}]$ & $0 \pm 0$ & $48.3 \pm 1.2 *$ & $46.6 \pm 1.3$ & $739.9 \mu \mathrm{M}$ \\
\hline UA $[800 \mu \mathrm{M}]$ & $0 \pm 0$ & $45.3 \pm 1.9 *$ & $49.9 \pm 2.1$ & \\
\hline $\mathrm{OA}[200 \mu \mathrm{M}]$ & $0 \pm 0$ & $87 \pm 3.9$ & $3.9 \pm 1.6$ & \\
\hline $\mathrm{OA}[400 \mu \mathrm{M}]$ & $0 \pm 0$ & $77.3 \pm 1.2 *$ & $14.6 \pm 1.3$ & $726.3 \mu \mathrm{M}$ \\
\hline $\mathrm{OA}[800 \mu \mathrm{M}]$ & $0 \pm 0$ & $50 \pm 3.6^{*}$ & $44.8 \pm 4$ & \\
\hline Acarbose $[200 \mu \mathrm{M}]$ & $0 \pm 0$ & $38.2 \pm 1.22 *$ & $57.8 \pm 1.3$ & \\
\hline Acarbose $[400 \mu \mathrm{M}]$ & $0 \pm 0$ & $13.1 \pm 0.75 *$ & $85.5 \pm 0.8$ & $173 \mu \mathrm{M}$ \\
\hline Acarbose $[800 \mu \mathrm{M}]$ & $0 \pm 0$ & $7 \pm 0.4^{*}$ & $96.7 \pm 0.18$ & \\
\hline
\end{tabular}

Effect of products obtained from the stems from S. polystachya on intestinal sucrose hydrolysis (ISH) inhibition test. Results shown as mean $\pm \operatorname{SEM}(n=6) .{ }^{*} p>0.05$ significantly different vs. sucrose group values. (Two-way ANOVA followed by Dunnett post hoc test) ACAR: acarbose; EESpS: ethanolic extract of stem; EtOAcFr: ethyl acetate fraction; UA: ursolic acid and $\mathrm{OA}$ : oleanolic acid; $\mathrm{IC}_{50}$ : half maximal inhibitory concentration.

Table 4. Quantity of glucose measured in the external aqueous medium, percent inhibition, and $\mathrm{CE}_{50}$ calculated after addition of treatments on intestinal glucose absorption (IGA) inhibition test.

\begin{tabular}{|c|c|c|c|c|}
\hline Treatment & $\begin{array}{c}\text { Glucose }\left(\mathrm{mg} / \mathrm{dL}^{-1}\right) \\
0 \mathrm{~h}\end{array}$ & Glucose $\left(\mathrm{mg} / \mathrm{dL}^{-1}\right)$ & $1 \mathrm{~h} \%$ Of Inhibition & $\mathrm{IC}_{50}$ \\
\hline Glucose (5\%) & $0 \pm 0$ & $217.3 \pm 6.1$ & - & - \\
\hline EESpS $\left[200 \mu \mathrm{g} / \mathrm{mL}^{-1}\right]$ & $0 \pm 0$ & $216 \pm 8.1$ & $0.5 \pm 3.7$ & \\
\hline EESpS $\left[400 \mu \mathrm{g} / \mathrm{mL}^{-1}\right]$ & $0 \pm 0$ & $192.5 \pm 3.7^{*}$ & $11.4 \pm 1.4$ & $1536.3 \mu \mathrm{g} / \mathrm{mL}$ \\
\hline EESpS $\left[800 \mu \mathrm{g} / \mathrm{mL}^{-1}\right]$ & $0 \pm 0$ & $167.7 \pm 9^{*}$ & $22.8 \pm 4.1$ & \\
\hline EtOAcFr $\left[200 \mu \mathrm{g} / \mathrm{mL}^{-1}\right]$ & $0 \pm 0$ & $175.3 \pm 19^{*}$ & $19.3 \pm 8.7$ & \\
\hline EtOAcFr $\left[400 \mu \mathrm{g} / \mathrm{mL}^{-1}\right]$ & $0 \pm 0$ & $162.7 \pm 1.8^{*}$ & $25.1 \pm 0.8$ & $697.3 \mu \mathrm{g} / \mathrm{mL}$ \\
\hline EtOAcFr $\left[800 \mu \mathrm{g} / \mathrm{mL}^{-1}\right]$ & $0 \pm 0$ & $176.5 \pm 7.1^{*}$ & $18.7 \pm 7.7$ & \\
\hline UA $[200 \mu \mathrm{M}]$ & $0 \pm 0$ & $270 \pm 31.3$ & 0 & \\
\hline $\mathrm{UA}[400 \mu \mathrm{M}]$ & $0 \pm 0$ & $188.3 \pm 4^{*}$ & $13.3 \pm 1.8$ & $966.6 \mu \mathrm{M}$ \\
\hline UA $[800 \mu \mathrm{M}]$ & $0 \pm 0$ & $132.3 \pm 5.3 *$ & $39.1 \pm 2.4$ & \\
\hline $\mathrm{OA}[200 \mu \mathrm{M}]$ & $0 \pm 0$ & $189.3 \pm 4^{*}$ & $12.8 \pm 1.8$ & \\
\hline $\mathrm{OA}[400 \mu \mathrm{M}]$ & $0 \pm 0$ & $132.3 \pm 2.2 *$ & $39.1 \pm 1$ & $849.3 \mu \mathrm{M}$ \\
\hline OA $[800 \mu \mathrm{M}]$ & $0 \pm 0$ & $121 \pm 6.5^{*}$ & $44.3 \pm 3$ & \\
\hline Canagliflozin $[200 \mu \mathrm{M}]$ & $0 \pm 0$ & $230 \pm 13.3$ & 0 & \\
\hline Canagliflozin [400 $\mu \mathrm{M}]$ & $0 \pm 0$ & $113.5 \pm 7.4^{*}$ & $49 \pm 3.1$ & $834.5 \mu \mathrm{M}$ \\
\hline Canagliflozin $[800 \mu \mathrm{M}]$ & $0 \pm 0$ & $124 \pm 5.7^{*}$ & $40.5 \pm 1.3$ & \\
\hline
\end{tabular}

Effect of products obtained from the stems from S. polystachya on intestinal glucose absorption (IGA) inhibition test. Results shown as mean $\pm \operatorname{SEM}(n=6) .{ }^{*} p>0.05$ Significantly different vs. glucose group values. (Two-way ANOVA followed by Dunnett post hoc test) ACAR: acarbose; EESpS: ethanolic extract of stem; EtOAcFr: ethyl acetate fraction; UA: ursolic acid and $\mathrm{OA}$ : oleanolic acid; $\mathrm{IC}_{50}$ : half maximal inhibitory concentration.

The results obtained are according to the in vivo OSuTT, OStTT, OGTT and OGaTT evaluations of oleanolic acid and ursolic acid that suggest the inhibition of the a-glucosidase enzymes and also a reduction in the glucose absorption mediated by the inhibition of SGLT1. Additionally, in silico studies were carried out in order to give additional support to the previous in vivo and ex vivo results. 


\subsection{In Silico Assays}

2.3.1. Molecular Docking Studies of Ursolic Acid (UA), Oleanolic Acid (OA) and Acarbose on $\alpha$-Glucosidase Enzyme

In order to show the possible interaction of UA and OA, a molecular docking study was carried out using as a target the $\alpha$-glucosidase enzyme, which is involved in the control of complex carbohydrate hydrolysis (the crystal structure of human lysosomal acid- $\alpha$-glucosidase was used: RCSB, PDB ID: 5 NN8). Moreover, acarbose was used as a control, and its binding site was compared with the UA and OA binding sites.

According to the results obtained, OA showed a greater affinity than UA to the binding site, with $\Delta \mathrm{G}$ values of $-6.41 \mathrm{kcal}-\mathrm{mol}^{-1}$ and $-5.48 \mathrm{kcal}^{-\mathrm{mol}^{-1}}$, respectively. OA and UA showed they had one polar interaction with each ligand, OA with Leu677, and UA with Asp518 residues (Table 5). In the case of acarbose, it showed the best affinity to the $\alpha$ glucosidase enzyme, with a $\Delta \mathrm{G}$ value of $-8.33 \mathrm{kcal}^{-\mathrm{mol}^{-1}}$. Moreover, this ligand showed eight polar interactions with Arg281, Asp282, Ala284, Arg600, Asp616, Gly651, Ser676 and Leu678. It is important to mention that the three ligands showed the same binding pocket; in the case of OA and acarbose, it showed a similar binding position. In the case of UA, this ligand binds in a different position than OA and acarbose (Figure 6).

Table 5. Interactions of oleanolic acid (OA), ursolic acid (UA) acarbose and canagliflozin with residues on the binding sites of $\alpha$-glucosidase and SGLT1 enzymes.

\begin{tabular}{|c|c|c|c|c|c|c|c|c|}
\hline \multirow{2}{*}{ Compound } & \multicolumn{4}{|c|}{$\alpha$-Glucosidase } & \multicolumn{4}{|c|}{ SGLT1 } \\
\hline & $\begin{array}{c}\Delta G \\
\left.\text { (kcal-mol }^{-1}\right)\end{array}$ & H-BR & NPI & RMSD & $\begin{array}{c}\Delta G \\
\left.\text { (kcal-mol }^{-1}\right)\end{array}$ & H-BR & NPI & RMSD \\
\hline $\begin{array}{c}\text { Oleanolic } \\
\text { acid }\end{array}$ & -6.41 & Leu677 & $\begin{array}{l}\text { Asp282, } \\
\text { Met519, } \\
\text { Phe525, } \\
\text { Leu650, } \\
\text { Gly651, } \\
\text { Ser676, } \\
\text { Leu678 }\end{array}$ & - & -10.55 & Gln451 & $\begin{array}{c}\text { Gly272, } \\
\text { Ala447, } \\
\text { Gln448, } \\
\text { Ser449, } \\
\text { Asp454, } \\
\text { Tyr455, } \\
\text { Glu503, } \\
\text { Thr508, } \\
\text { Cys522, } \\
\text { Gly523, } \\
\text { Val524, } \\
\text { His525, } \\
\text { Tyr526 }\end{array}$ & - \\
\hline Ursolic acid & -5.48 & Asp518 & $\begin{array}{l}\text { Trp376, } \\
\text { Trp481, } \\
\text { Met519, } \\
\text { Asp616, } \\
\text { Phe649, } \\
\text { Leu650, } \\
\text { His674 }\end{array}$ & - & -9.65 & $\begin{array}{l}\text { Gln451, } \\
\text { Gly523 }\end{array}$ & $\begin{array}{c}\text { Asp273, } \\
\text { Ala447, } \\
\text { Gln448, } \\
\text { Ser449, } \\
\text { Asp454, } \\
\text { Tyr455, } \\
\text { Ser458, } \\
\text { Thr508, } \\
\text { Cys522 }\end{array}$ & - \\
\hline Acarbose & -8.33 & $\begin{array}{l}\text { Arg281, } \\
\text { Asp282, } \\
\text { Ala284, } \\
\text { Arg600, } \\
\text { Asp616, } \\
\text { Gly651, } \\
\text { Ser676, } \\
\text { Leu678 }\end{array}$ & $\begin{array}{l}\text { Met519, } \\
\text { Trp618, } \\
\text { Leu650 }\end{array}$ & 1.87 & - & - & - & - \\
\hline Canagliflozin & - & - & - & - & -11.04 & $\begin{array}{c}\text { Met283, } \\
\text { Thr287, } \\
\text { Tyr290, } \\
\text { Trp291, Gln } \\
457\end{array}$ & $\begin{array}{c}\text { Asn78, } \\
\text { His83, } \\
\text { Phe101 }\end{array}$ & 1.44 \\
\hline
\end{tabular}

$\Delta \mathrm{G}$ : Binding energy $\left(\mathrm{kcal} / \mathrm{mol}^{-1}\right)$; H-BR: H-binding residues; NPI: nonpolar interactions; Asp: aspartate; Asn: asparagine; Arg: arginine; Gln: glutamine; Lys: lysine; Thr: threonine; Ser: serine; Trp: tryptophan; Leu: leucine; His: histidine; Gly: glycine; Glu: glutamic acid; Ile: isoleucine; Tyr: tyrosine; Phe: phenylalanine. 


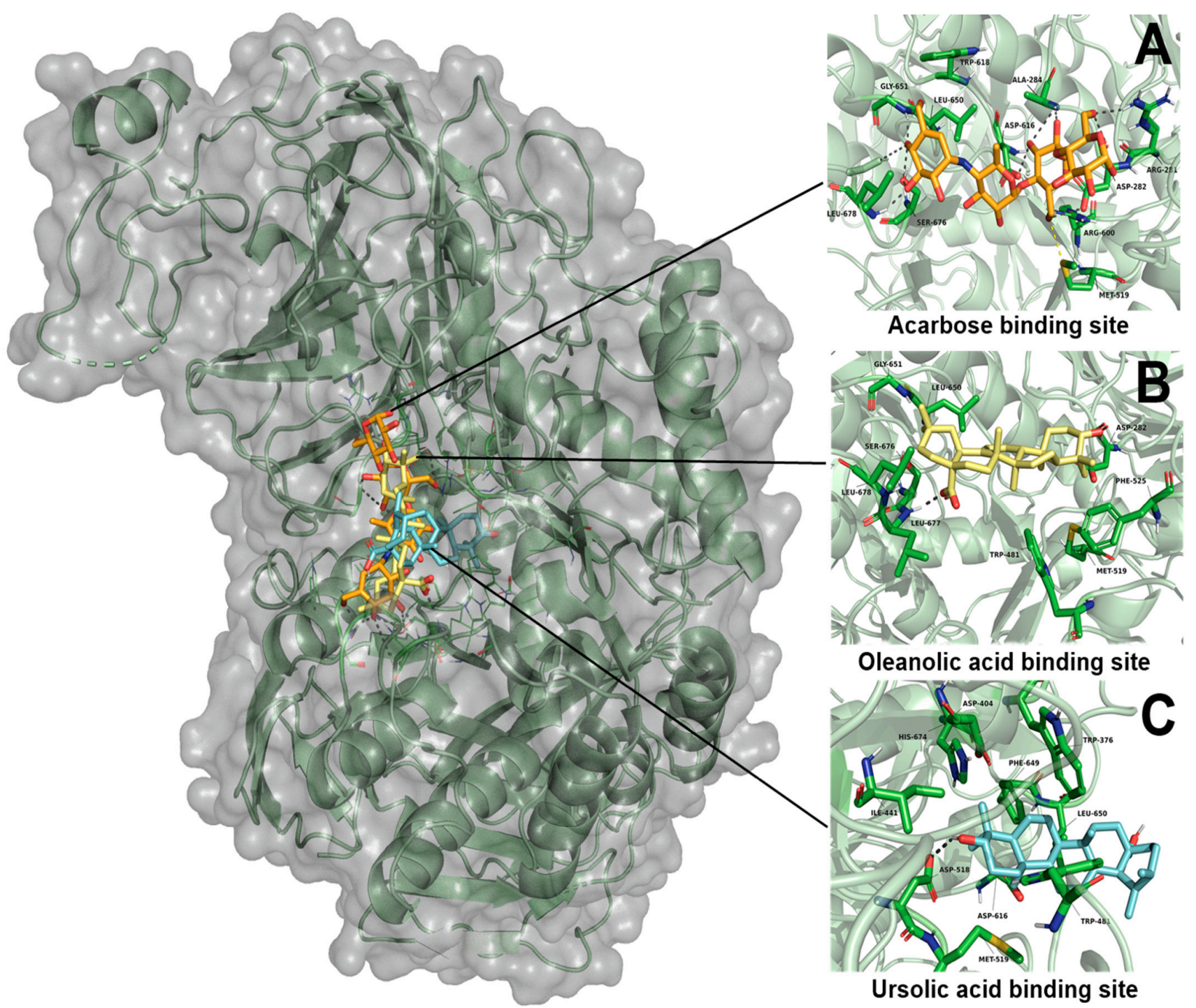

Figure 6. Results of molecular docking on $\alpha$-glucosidase enzyme. (A) Interaction of acarbose and its binding site position; (B) interaction of oleanolic acid and its binding site position; (C) interaction of ursolic acid and its binding site position.

2.3.2. Molecular Docking Studies of Ursolic Acid (UA), Oleanolic Acid (OA) and Canagliflozin on SGLT1 Cotransporter

The second molecular docking study was carried out using the SGLT1 cotransporter as a target. SGLT1 is involved in the control of glucose absorption (the crystal structure of human sodium/glucose cotransporter, UniProt ID: P13866). Canagliflozin was used as a control in order to compare the binding site with UA and OA.

UA showed an affinity in a different site than canagliflozin (Figure 7), with a $\Delta G$

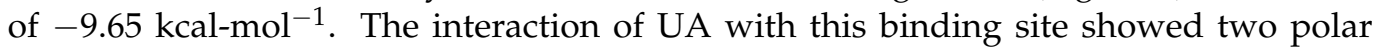
interactions with Gln451 and Gly523. In the case of OA, this ligand showed the same binding position as UA. Additionally, OA had a $\Delta \mathrm{G}$ of $-10.55 \mathrm{kcal}^{-\mathrm{mol}^{-1}}$ with only one polar interaction with Gln 451 . On the other hand, canagliflozin showed the best affinity to

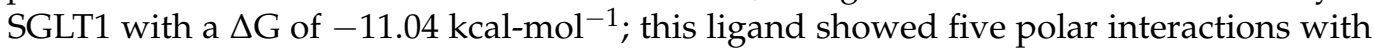
Met283, Thr287, Tyr290, Trp291 and Gln 457 (Table 5). 


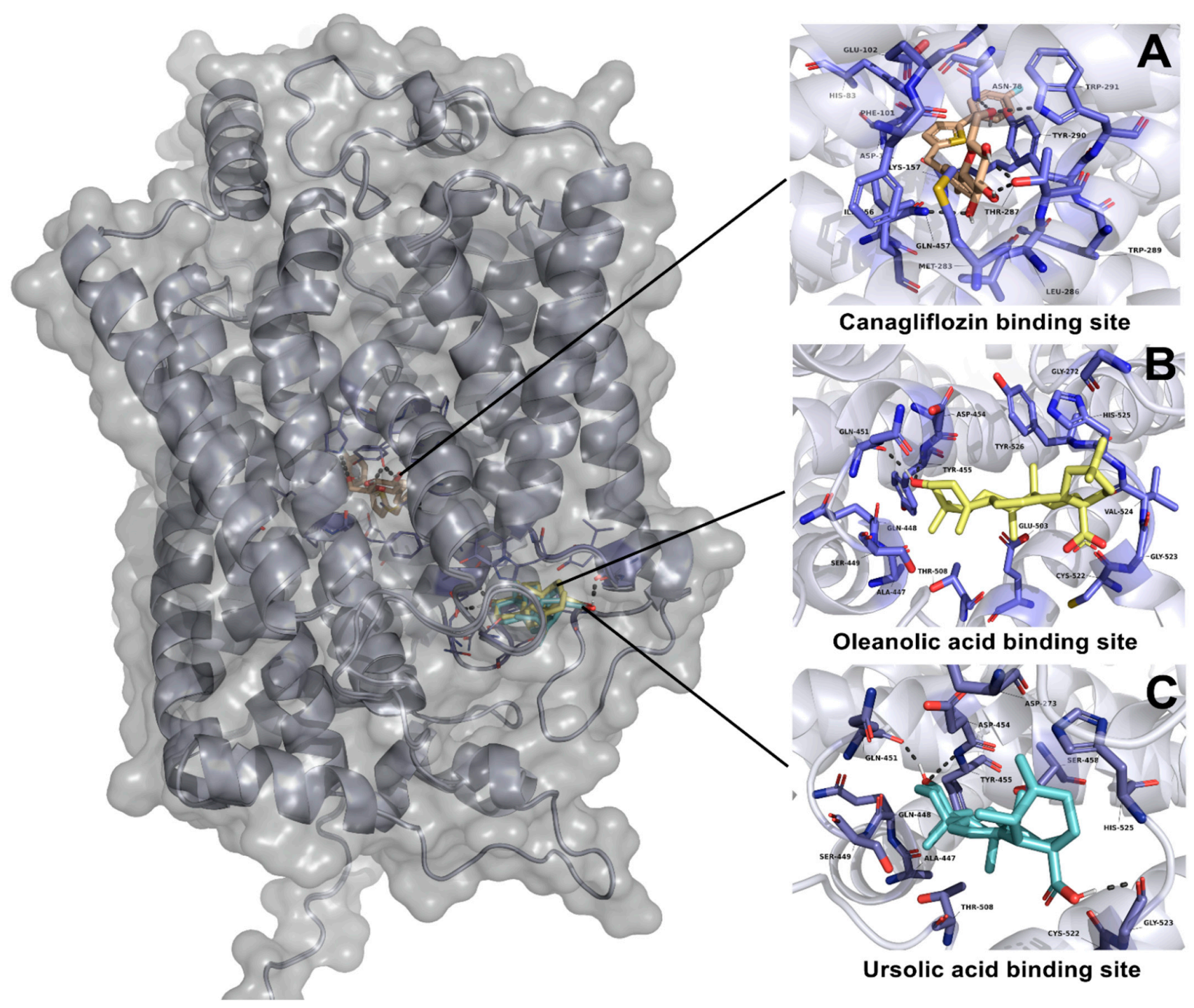

Figure 7. Results of molecular docking on SGLT1 cotransporter. (A) Interaction of canagliflozin and its binding site position; (B) interaction of oleanolic acid and its binding site position; $(\mathbf{C})$ interaction of ursolic acid and its binding site position.

\section{Discussion}

Several species from the Lamiaceae family have been proposed to have an antidiabetic effect, ursolic acid, oleanolic acid and $\beta$-sitosterol being the products related with this activity $[25,26]$. In the case of ursolic acid and oleanolic acid, they have been described as potential $\alpha$-glucosidase inhibitors using in vitro and in silico experiments [29]. Considering the above and taking into account the constant need for the development of new drugs to treat the hyperglycemia caused by diabetes mellitus, the potential antidiabetic effect of $S$. polystachya (a species that belongs to the Lamiaceae family) was evaluated, in consideration of a chemotaxonomic criterion. The evaluation of the ethanolic extract obtained from the stems of S. polystachya was carried out using activity-guided fractionation as a strategy, with in vivo, ex vivo and in silico assays.

Initially, the toxicological study (according to the OCDE's Guideline 423) of the extract obtained was carried out, and the results showed that the ethanolic extract of the stem from S. polystachya did not cause behavior alterations, visible tissue damage, modifications in the body or organ weight. According to the Globally Harmonized Classification System for chemical substances and mixtures (GSH) adopted by the OECD [37], the extract is classified as a nontoxic class $5 \mathrm{drug}$, and is considered a nontoxic substance [37]. 
Once the toxicity of our sample was evaluated, the evaluation in diabetic mice was carried out. The experimental diabetes mellitus type 2 (DM2) was induced using the streptozocin-nicotinamide (STZ-NA) model [13]. The administration of STZ-NA induces diabetes due to selective pancreatic $\beta$-cell cytotoxicity by STZ [38,39], followed by $\beta$-cell protection generated by the administration of NA [40]. Finally, the model results in a partial inhibition of insulin secretion [41]. Therefore, the NA-STZ-induced diabetes model is characterized by hyperglycemia and glucose intolerance, such as in T2D. It is a valuable model for the study of potential antidiabetic drugs, including medicinal plants [23,27,42]. The administration of the extract from the stems from S. polystachya (EESpS) generated a significative reduction in hyperglycemia in the animals with experimental DM2. These results are similar to those reported in other vegetal species from the Lamiaceae family [25-30], where the authors describe the diminution of hyperglycemia after a single administration of ethanolic extracts from the leaves of other Lamiaceae species. Moreover, in some studies, a subchronic administration of extracts results in an adequate control of hyperglycemia accompanied by a reduction in the glycated hemoglobin percentage [20].

EESpS was fractionated and the obtained fractions were also evaluated in diabetic mice, with the result that EtOAcFr significantly reduced the hyperglycemia in the DM2 model. Thus, this fraction was submitted to a secondary fractionation resulting in ten secondary fractions, of which SeFr6 was the most active. To identify the compounds responsible for the observed effects of the $S$. polystachya stem extract, a phytochemical screening from EtOAcFr was performed. HPLC-diode array detection (DAD) allowed us to determine the presence of ursolic and oleanolic acid, two terpenoids that have been described as $\alpha$-glucosidase inhibitors in in vitro and in silico diabetic models [29]. In this sense, 42 terpenoids previously reported in Salvia species were checked in EtOAcFr and SeFr6, including polystachynes A, B, and D, as well as linearolactone, which was previously isolated from S. polystachya [35]; however, only the presence of ursolic acid and oleanolic acid (UA and OA, respectively) was identified. It is important to mention that the isolation of UA and OA in this vegetal species has not been reported yet. When these products were evaluated in the DM2 model, they showed significant reductions in blood glucose levels. Some authors have reported that UA acted as an effective insulin mimetic and as an insulin sensitizer [43], increasing insulin vesicle translocation, insulin secretion and augmented glycogen content [44]. Based on these reports, the effect observed in EESpS could be partially explained. To continue the study, the reduction of complex carbohydrate hydrolysis and the absorption of simple carbohydrates mediated by $\alpha$-glucosidases and SGLT1, respectively were addressed.

The $\alpha$-glucosidase inhibitors can delay the liberation of glucose from dietary complex carbohydrates, retarding glucose absorption and lowering the postprandial blood glucose peak [45]. In the present research, the $\alpha$-glucosidase inhibitory effect was studied using oral sucrose and starch tolerance tests (OSuTT and OstTT, respectively). In these assays, the postprandial glucose peak after the complex carbohydrate load was measured to determine the possible inhibition of these enzymes which are involved in the hydrolysis of different types of glycosidic bonds (sucrose: $\alpha-1,2$; starch: $\alpha-1,4$ ) then EESpS EtOAcFr. UA and OA significantly reduced the postprandial peak after sucrose or starch administration, possibly due to an inhibitory effect on $\alpha$-glucosidase, preventing hyperglycemia. However, to corroborate the results obtained, ex vivo and in silico studies were carried out.

The second mechanism of action evaluated was that of the type 1 inhibitor of sodiumglucose cotransporters (SGLT). These cotransporters are part of a subgroup of the solute carrier group (SLC5), which includes six members that differ in their preferences for sugar binding, and all the members of this family use the electromechanical gradient of sodium to transport sugar molecules against a chemical gradient into cells. Among the most studied of the SLC5 family, SGLT1 and 2 are highlighted. SGLT2 is expressed mostly in early renal proximal tubules and is responsible for $>90 \%$ of the renal reabsorption of filtered glucose (160-180 g/day) and SGLT1 plays an important role in glucose absorption from the intestinal lumen into the epithelial cells of the small intestine [46]. In order to determine the 
effect of the products isolated from the stems of S. polystachya, oral glucose and galactose tolerance tests were carried out (OGTT and OGaTT, respectively) with the objective of determining whether the treatments inhibited the SGLT1 expressed in the membrane of enterocytes, which are responsible for mediating intestinal glucose absorption [47-49]. It is possible that the reduction of the postprandial peak after the carbohydrate load observed in EESpS, EtOAcFr, UA and OA treatments works in conjunction with the inhibition of $\alpha$-glucosidases shown in the previous assays. Moreover, in the case of EESpS and EtOAcFr, one or more compounds might inhibit some of the glucose transporters involved in its absorption, with UA and OA being partly responsible for the effects observed. Additional studies to identify other compounds and determine their possible synergic action are mandatory. These results support that $S$. polystachya contains compounds with the capacity to inhibit $\alpha$-glucosidases.

The next step was conducting the ex vivo assays. These studies were carried out with the objective of corroborating the activity demonstrated in the in vivo assays. First, in the intestinal sucrose hydrolysis assay (ISH), all the products significantly reduced the quantity of glucose in the aqueous external medium. This can be interpreted as a possible inhibition of the $\alpha$-glucosidases present in the portion of intestine used. The $\mathrm{IC}_{50}$ calculated in all the treatments showed the potential inhibitory effect of the hydrolysis of complex carbohydrates mediated by $\alpha$-glucosidases. Despite acarbose showing a minor $\mathrm{IC}_{50}$ value, the results shown by the products isolated from the stems of $S$. polystachya are important. Authors describe that UA and OA isolated from Salvia africana-lutea exhibited promising $\alpha$-glucosidase inhibitory activity, and the inhibition kinetic analysis showed $\mathrm{IC}_{50}$ values in the range of $24.7-188.7 \mu \mathrm{M}$ compared to $945.5 \mu \mathrm{M}$ for acarbose. It has been proposed that the presence of a methyl group at the $\mathrm{C}-19$ position had a positive effect on the inhibitory activity of UA [50].

The absorption of simple carbohydrates was evaluated with the intestinal glucose absorption assay (IGA). After the addition, all the products showed a significant reduction in the total glucose absorbed. This result corroborates the activity observed in OGTT and OGaTT. In regard to the $\mathrm{IC}_{50}$ obtained for all the treatments, UA and OA (966.6 and $849.3 \mu \mathrm{M}$, respectively) were similar to the $\mathrm{IC}_{50}$ obtained with the control drug canagliflozin $(834.5 \mu \mathrm{M})$. The in vivo and ex vivo results suggest that the antihyperglycemic activity observed after the administration of the products obtained from the stems of S. polystachya can be mediated by the inhibition of the hydrolysis of complex carbohydrates and the absorption of simple carbohydrates.

Finally, in silico studies were carried out with the objective of determining the possible binding site of UA and OA in the $\alpha$-glucosidases and SGLT1 cotransporter. In the case of the enzyme $\alpha$-glucosidase, UA showed a $\Delta \mathrm{G}$ value of $-5.48 \mathrm{kcal}^{-\mathrm{mol}^{-1}}$; moreover, this product shares some binding amino acid residues (Asp616 and Leu650) with acarbose. Despite the binding position not being the same (Figure 6), this position may help to avoid $\alpha$-glucosidase activity. Perhaps, as some authors describe, the methyl group at the C-19 position could be involved in the binding position [50]. Molecular dynamic studies need to be carried out to observe if this binding position avoids the interaction between sucrose

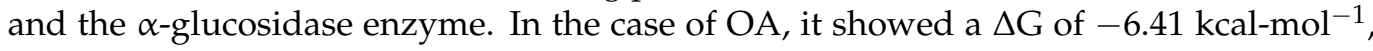
and shares six binding amino acid residues (Asp282, Met519, Leu650, Gly651, Ser676 and Leu678) with acarbose. It is important to mention that the binding position is very similar to acarbose. This may explain the results obtained during the in vivo OSTT and OStTT and the ex vivo ISH assays, where OA reduced the postprandial peak of glucose, and also reduced the quantity of glucose absorbed in ISH with a lower $\mathrm{CE}_{50}(726.3 \mu \mathrm{M})$ than that obtained in UA $(739.9 \mu \mathrm{M})$.

In regard to molecular docking studies with SGLT1, UA ( $\Delta \mathrm{G}$ of $-9.65 \mathrm{kcal}^{-\mathrm{mol}^{-1}}$ ) and $\mathrm{OA}\left(\Delta \mathrm{G}\right.$ of $-10.51 \mathrm{kcal}^{-\mathrm{mol}^{-1}}$ ), each showed important binding values; however, the binding position was not similar to that obtained in the molecular docking of canagliflozin $\left(\Delta \mathrm{G}\right.$ of $\left.-11.04 \mathrm{kcal}^{-\mathrm{mol}^{-1}}\right)$, which was shown to bind in a different place in the SGLT1 cotransporter. According to the results obtained during the in vivo and ex vivo studies, AU 
and OA reduced the postprandial peak of glucose in OGTT and OGaTT, and also showed an important $\mathrm{CE}_{50}$ (966.6 and $849.3 \mu \mathrm{M}$, respectively). There is the possibility that they inhibit the SGLT1 activity in an allosteric site. However, the next step of the investigation is to perform molecular dynamic studies accompanied by enzyme inhibition studies in order to confirm the results obtained.

UA and OA are pentacyclic triterpenoids, isomers that differ in the position of a methyl residue connected to the C-19 or C-20 in the E ring. These modifications result in different pentacyclic triterpenes; the former is oleanane, whereas the latter is ursane [51,52]. These compounds naturally occur in many species of plants; in particular, they have been reported in some plants of the Salvia genus. The OA from the $S$. moorcraftiama has been reported to have the potential to reduce hyperglycemia and the complications of diabetes [23,31,53,54], and have great permeability in the small bowel [55-58], which were proposed as $\alpha$-glucosidase inhibitors [59-62]. The present study demonstrates for the first time the isolation of UA and OA in S. polystachya. In addition, this study evaluates their antihyperglycemic activity with a possible dual inhibitory activity effect over $\alpha$-glucosidase enzymes and the SGLT1 cotransporter.

\section{Materials and Methods}

\subsection{General Information}

Ethanol anhydrous (CC:15568604) and ethyl acetate (CC:10382681) were purchased from J.T. Baker (Thermo Fisher Scientific, Waltham, MA, USA). Streptozotocin $(\geq 75 \% \alpha-$ anomer basis, PN: S0130-5G), nicotinamide ( $\geq 99.5 \%, \mathrm{PN}: 47865-\mathrm{U})$, ursolic acid ( $\geq 90 \%, \mathrm{PN}$ : U6753-500MG), oleanolic acid ( $\geq 97 \%$, PN: O5504-500MG), sucrose ( $\geq 99.5 \%$ GC, PN: S9378$1 \mathrm{Kg}$ ), acetonitrile HPLC gradient grade ( $\geq 99.9, \mathrm{PN}: 34851-1 \mathrm{~L})$ and ethanol HPLC gradient grade (100\%, PN: 459828-1L) were purchased from Sigma-Aldrich (St. Louis, MI, USA). Acarbose (Glucobay, tablets of $50 \mathrm{mg}$, Bayer Mexico S.A. DE C.V.), canagliflozin (Invokana, tablets of $300 \mathrm{mg}$, Janssen-Ortho LLC, Puerto Rico) and glibenclamide (Glibenclamide, tablets of $5 \mathrm{mg}$, Silanes, Mexico) were purchased from the local pharmacy. Buffer solution (citric acid/sodium hydroxide/hydrogen chloride, pH 4.00, CC: 109445). Saline solution 0.9\% (solution $1000 \mathrm{~mL}$ ) and DX-5 glucose solution 5\% (solution $500 \mathrm{~mL}$ ) were purchased from PISA Pharmaceutics (Pisa, Mexico City, Mexico).

\subsection{Plant Material}

S. polystachya stems were collected in San Gregorio Atlapulco, Xochimilco $\left(19^{\circ} 14^{\prime} 9.919^{\prime \prime}\right.$ N 99 $2^{\prime} 53.879^{\prime \prime}$ W), Mexico City, Mexico. The plant was identified by the M.Sc. Santiago Xolalpa in the Herbarium of the Mexican Institute of Social Security (IMSSM-Herbarium), with voucher specimen number 16386. The sample was cleaned and air-dried at ambient temperature, and finally, the dried samples were ground using a laboratory grinder (model M-22-RW, Fundición Torrey, Apodaca, Nuevo León, México).

\subsection{Preparation of Ethanolic Extracts, Fractionation, and Characterization of Ursolic and Oleanolic Acid}

The stems $(695.1 \mathrm{~g})$ from $S$. polystachya were extracted with $\mathrm{EtOH}(6 \mathrm{~L} \times 3)$ for one week, and filtered (Whatman No.1). The extract filtered was evaporated to dryness using a rotary evaporator at $35^{\circ} \mathrm{C}$ (Buchi, Flawil, Switzerland), to obtain $16.9 \mathrm{~g}$ of ethanolic extract from stems (EESpS, 2.4\% yield); this was subjected to biological assays. Once the antihyperglycemic activity of EESpS was examined, it was submitted for partitioning. Briefly, a portion of EESpS (50 g) was suspended in 10\% EtOH-water (100 mL) and successively partitioned with EtOAc $(150 \mathrm{~mL} \times 2)$ to obtain $19.8 \mathrm{~g}$ of EtOAc fraction (EtOAcFr). The aqueous residual layer was collected to obtain $28.9 \mathrm{~g}$ of aqueous residual fraction (AqRFr).

The antihyperglycemic activity was associated with EtOAcFr, then a portion (450 mg) was submitted for separation by open column chromatography $(2 \mathrm{~cm} \times 34.5 \mathrm{~cm})$, packed with silica gel 60 (70-230 mesh), and eluted with solvents of crescent polarity: hexane, hexane/ethyl acetate, and ethyl acetate/methanol. Ten secondary fractions were obtained: 
SeFr1 (26. 9 mg), SeFr2 (13.1 mg), SeFr3 (218 mg), SeFr4 (57.4 mg), SeFr5 (128.4 mg), SeFr6 (194.9 mg), SeFr7 (49.4 mg), SeFr8 (12.3 mg), SeFr9 (123.4 mg), and SeFr10 (111.4 mg).

SeFr6 was the fraction with the best antihyperglycemic activity. It was then analyzed using HPLC-diode array detection (DAD) (Waters Agilent, 5301 Stevens Creek Blvd Santa, Clara, CA 95051, USA). The analysis was performed using an HPLC-DAD Waters 2795 liquid chromatograph system coupled with a Waters 996 photodiode array detector and an analytical Millennium 3.1 workstation equipped with a C18 analytical column (Waters, Mexico City, Mexico) with dimensions of $250 \mathrm{~mm} \times 4.6 \mathrm{~mm}$ and a particle size of $5 \mu \mathrm{m}$ (Spherisorb S50D52, Waters Corporation, Milford, MA, USA). For the analysis, $50 \mathrm{mg}$ of the SeFr6 was dissolved in $10 \mathrm{~mL}$ of $\mathrm{EtOH}$, and $20 \mu \mathrm{L}$ of the sample was injected. For elution, a system comprising a binary mobile phase of acetonitrile $100 \%$ (solvent $\mathrm{A}$ ) and acetic acid $2 \%$ (solvent $B$ ) in water was used. The chromatograph's operating conditions were programmed to give the following linear gradient of 80 (A)/20 (B) for $15 \mathrm{~min}$ with a flow rate of $0.8 \mathrm{mLmin}^{-1}$ of the mobile phase. The detections were made at a wavelength ( $\lambda$ ) from 200 to $400 \mathrm{~nm}$ at room temperature and a total elution time of $25 \mathrm{~min}$. At the end, the data collected were plotted, and the chromatograms shown in the results section show an absorbance of $220 \mathrm{~nm}$, due to the samples only showing an absorbance at this wavelength. The presence of substances in the SeFr6 fraction was confirmed by comparing the retention times with the standards library. The reference standards of the ursolic acid (UA) and oleanolic acid (OA) used had a purity degree of 90 and 97, respectively. These were prepared and analyzed separately under the same conditions described above. In all cases, the water used was of HPLC quality and purified in a Milli-Q system (Millipore, Bedford, MA, USA).

\subsection{Experimental Animals}

Male and female BALB/c mice ( $21 \pm 3 \mathrm{~g}$ ) provided by the animal center at the 21st Century National Medical Center laboratory at the Mexican Institute of Social Security (CMN-SXXI-IMSS) were used. The animals were maintained at $22 \pm 1{ }^{\circ} \mathrm{C}$, with light/dark cycles of $12 \mathrm{~h}$, and free access to water and food (standard rodent diet, LabDiet Formulab Diet 5008). The studies in rodents were performed in conformity with the Mexican Official Rule for Animal Care and Handling NOM-062-ZOO-1999 [63]. All investigations were conducted with the approval of the Specialty Hospital Ethics Committee of Centro Médico Nacional Siglo XX at IMSS (register: R-2020-3601-007).

\subsection{In Vivo Assays}

\subsubsection{Acute Toxicity Study}

The acute oral toxicity study of the extract from the stems from S. polystachya was conducted in compliance with OECD's Guideline 423 (Organization for Economic Cooperation and Development) [37]. BALB/c female mice (20-30 g), with free access to water and that were fasted overnight, were used. Animals were grouped as follows: the control group, which was treated with the vehicle ( $2 \%$ Tween 80 in water), and three groups treated with EESpS at 50, 300 and $200 \mathrm{mg} / \mathrm{kg}^{-1}$. The extract was dissolved in $2 \%$ Tween 80 in water, and all treatments were administered per os with an esophageal cannula. After the administration of the treatments, the animals were observed for $4 \mathrm{~h}$ and then for 14 days in order to record possible toxic effects, such as changes in behavior, body weight, urination, food intake, water intake, respiration, temperature, and eye and skin color, as well as convulsions, tremors, constipation, among others. At the end of the study (day 14), the animals were sacrificed, and the internal organs (stomach, gut, kidney, liver, and pancreas) were extracted, weighed, observed macroscopically and compared against the control group. The organs' relative weights (ORW) were measured in accordance with the ORW formula [64].

$$
\text { Organ Relative Weight }=\frac{\text { Absolute weight }(g)}{\text { Mouse body weight at day } 14} \times 100
$$




\subsubsection{Induction of Experimental Type 2 Diabetes}

Experimental diabetes was induced by the streptozocin-nicotinamide (STZ-NA) model $[12,13,20]$. On the first day, mice fasted overnight $(16 \mathrm{~h})$ were used, and they intraperitoneally received (IP) $100 \mathrm{mg} / \mathrm{kg}^{-1}$ of STZ dissolved in a cold pH 4 buffer solution, and $30 \mathrm{~min}$ later, $240 \mathrm{mg} / \mathrm{kg}^{-1}$ of NA dissolved in saline solution were administered IP. Once STZ and NA were administered, the animal food was put out. On day 3, fasted mice $(16 \mathrm{~h})$ were administered a second dose of $100 \mathrm{mgkg}^{-1} \mathrm{STZ}$. After administration, the animal food was put out and a $10 \%$ sucrose solution was used over two days. On day 5 , the sucrose solution was withdrawn and substituted with water ad libitum. Then, $72 \mathrm{~h}$ later, the glycemia was measured by an enzymatic glucose oxidase method, using a glucometer (Evolution, Infopia USA, LLC, Titusville, FL, USA) [20]. Those animals with blood glucose levels between $250-350 \mathrm{mg} / \mathrm{dL}$ were considered for experiments.

4.5.3. Acute Effect of Ethanolic Extract from Stems of S. polystachya and Its Products over Glycemia

This assay was conducted in diabetic mice (DM), and the animals were randomly divided into 12 groups $(n=6)$, as follows: normal mice (NM) and DM control groups, both treated with the vehicle, (2\% Tween 80 in water); and ten groups treated with EESpS (50, 100 and $200 \mathrm{mg} / \mathrm{kg}^{-1}$ ), AqRFr, EtOAcFr, SeFr6, ursolic acid (UA) and oleanolic acid (OA) $\left(50 \mathrm{mg} / \mathrm{kg}^{-1}\right)$. In order to compare the antihyperglycemic activities of the products isolated from $S$. polystachya, the control drugs glibenclamide and acarbose $\left(50 \mathrm{mg} / \mathrm{kg}^{-1}\right)$ were used. All treatments were dissolved in Tween 80 (2\% in water) as the vehicle and given in a single oral administration. Blood samples were obtained by puncturing the vein caudal before, and $0,30,60,90$ and 120 min after the administration of the treatments. Blood glucose levels $(\mathrm{mg} / \mathrm{dL})$ were determined by the enzymatic glucose oxidase method (Evolution, Infopia USA, LLC) [20].

4.5.4. Oral Sucrose and Starch Tolerance Tests of the Products Obtained from Stems from S. polystachya

Oral sucrose and starch tolerance tests (OSuTT and OStTT, respectively) were conducted in male normoglycemic fasted mice. These were randomly divided into seven groups $(n=6)$, as follows: the vehicle group treated with the vehicle $(2 \%$ Tween 80 in water); the sucrose group treated with the vehicle + sucrose $\left(3 \mathrm{~g} / \mathrm{kg}^{-1}\right)$; five groups treated with EESpS (300 mg/ $\left.\mathrm{kg}^{-1}\right)$, EtOAcFr $\left(200 \mathrm{mg} / \mathrm{kg}^{-1}\right), \mathrm{OA}$ and UA $\left(50 \mathrm{mg} / \mathrm{kg}^{-1}\right)$; and a group treated with acarbose $\left(50 \mathrm{mg} / \mathrm{kg}^{-1}\right)$, an $\alpha$-glucosidase inhibitor, used as the pharmacological control. All samples were solubilized with $2 \%$ Tween 80 in water and administered orally. Thirteen minutes after the administration of treatments, a sucrose load $\left(3 \mathrm{~g} / \mathrm{kg}^{-1}\right)$ was administered to the groups. Once administered, the animals were maintained in metabolic cages during the assay. Blood glucose levels were measured by puncturing the caudal vein before the administration of treatments $(0 \mathrm{~h})$, and 30,60, 90, and 120 min after administration. Blood glucose levels $(\mathrm{mg} / \mathrm{dL})$ were determined by the enzymatic glucose oxidase method (Evolution, Infopia USA, LLC) [20].

4.5.5. Oral Glucose and Galactose Tolerance Tests of the Products Obtained from the Stems from S. polystachya

Oral glucose and galactose tolerance tests (OGTT and OGaTT, respectively) were carried out in the same conditions as the OSuTT and OStTT. The grouping was the same, with the exception that in OGTT and OGaTT, canagliflozin (50 mg $\left./ \mathrm{kg}^{-1}\right)$ was used as the pharmacological control, and a glucose load $\left(1.5 \mathrm{~g} / \mathrm{kg}^{-1}\right)$ was used. The blood collection and measurement were carried out following the same conditions as OSuTT and OStTT. 


\subsection{Ex Vivo Assays}

Determination of the Inhibition of Intestinal Sucrose Hydrolysis and Glucose Absorption of the Products Obtained from the Stems from S. polystachya Cav. and Its Products

The intestinal sucrose hydrolysis (ISH) and intestinal glucose absorption (IGA) assays were conducted according to Valdes et al. [13]. Male Sprague-Dawley rats were used for the assays. The rats were sacrificed according to NOM0062-ZOO-1999. The proximal small intestine (SI) was removed and the first portions of the SI (jejunum and duodenum) were cut into $3 \mathrm{~cm}$ portions. These portions were tied on their ends with a nonabsorbable silk suture (Ethicon, Johnson \& Johnson, Somerville, MA, USA). For the ISH assay, the group treatments $(n=6)$ were prepared as follows: EESpS, EtOAcFr $\left(200,400\right.$ and $\left.800 \mu \mathrm{g} / \mathrm{mL}^{-1}\right)$, ursolic acid, oleanolic acid, and acarbose (200, 400 and $800 \mu \mathrm{M})$. The samples were dissolved in $1.5 \mathrm{~mL}$ of $15 \%$ sucrose solution as a vehicle. Additionally, a control group was treated only with the vehicle. All the treatments were injected with an insulin syringe inside the $3 \mathrm{~cm}$ SI portions previously made in a $0.5 \mathrm{~mL}$ volume. Immediately, SI portions were placed in a Petri dish with $15 \mathrm{~mL}$ of distilled water as the external aqueous medium (EAM) and incubated for $2 \mathrm{~h}$ at $37^{\circ} \mathrm{C}$ with constant agitation. The quantities of glucose absorbed in the SI were measured in the EAM $1 \mathrm{~h}$ after adding the treatments using the glucose oxidase method.

In the case of the IGA assay, it was conducted under similar conditions to the ISH test, with the exception that canagliflozin $(200,400$ and $800 \mu \mathrm{M})$ was used as the pharmacological control, the samples were dissolved in $1.5 \mathrm{~mL}$ of $5 \%$ glucose solution, and the measurements were carried out $1 \mathrm{~h}$ after the incubation of the intestines. Finally, during the ISH and IGA assays, the results were compared and normalized with the control group at the different measurement times and the half maximal inhibitory concentrations $\left(\mathrm{IC}_{50}\right)$ were calculated.

\subsection{In Silico Assays}

The chemical structure of the ligands ursolic acid (CID: 64945), oleanolic acid (CID: 10494) canagliflozin (CID: 24812758) and acarbose (CID: 41774) were retrieved from the chemical library PubChem (https: / / pubchem.ncbi.nlm.nih.gov/) (accessed on 6 November 2021); these were optimized and submitted to energetic and geometrical minimization using the Avogadro software [65]. Two different targets involved in the control of hyperglycemia were used, $\alpha$-glucosidase (crystal structure of human lysosomal acid- $\alpha$-glucosidase was used (RCSB, PDB ID: 5NN8)) and the SGLT-1 (crystal structure of human sodium/glucose cotransporter, UniProt ID: P13866) enzyme. These were retrieved from the Protein Data Bank (http:/ / www.rcsb.org/ (accessed on 29 November 2021)) and UniProt database (https: / / www.uniprot.org) (accessed on 6 November 2021). The total molecules of water and ions that were not needed for catalytic activity were stripped to preserve the entire protein. All polar hydrogen atoms were added, ionized in a basic environment $(\mathrm{pH}=7.4)$, and Gasteiger charges were assigned. The computed output topologies from the previous steps were used as input files for docking simulations.

The molecular docking experiments were carried out using AutoDock 4.2 software [66], and the search parameters were as follows: a grid-base procedure was employed to generate the affinity maps delimiting a grid box of $126 \times 126 \times 126 \AA 3$ in each space coordinate, with a grid point spacing of $0.375 \AA$. The Lamarckian genetic algorithm was employed as a scoring function with a randomized initial population of 100 individuals and a maximum number of energy evaluations of $1 \times 107$ cycles. The analysis of the interactions in the enzyme/inhibitor complex was visualized with PyMOL software (the PyMOL Molecular Graphics System, Ver 2.0, Schrödinger, LLC). The validation of the molecular docking was carried out by re-docking the co-crystallized ligand in the receptors. The lowest energy pose of the co-crystallized ligands was superimposed and it was observed whether it maintained the same binding position. The RMSD were calculated and a reliable range within $2 \AA$ is reported. 


\subsection{Statistical Analysis}

Data are expressed as means \pm standard error of the mean (SEM). The statistical analyses were determined using GraphPad Prism software (version 8.0.2, GraphPad Inc., La Jolla, CA, USA). One-way ANOVA evaluations were carried out followed by a post hoc Dunnett test. In all the cases, $p<0.05$ was considered a statistically significant difference between the mean groups.

\section{Conclusions}

EESpS of S. polystachya, EtOAcFr, SeFr6 and the UA and OA identified from EtOAcFr reduced blood glucose levels in diabetic mice. This activity was confirmed through in vivo, ex vivo and in silico studies. The complete results of the analysis suggest that the antidiabetic activity of the products from the stems from S. polystachya is mediated in part by $\alpha$-glucosidase enzyme inhibition and SGLT1 cotransporter inhibition. This research supports the phytochemical and pharmacological bases of S. polystachya and its use as a source of potential antidiabetic agents for T2D control.

Author Contributions: Conceptualization, R.O. and F.C.; methodology, R.O., M.V., F.J.A.-A., Á.F.-B., C.V. and E.B.; validation and formal analysis, R.O., M.V., F.J.A.-A., Á.F.-B., C.V., E.B. and F.C.; investigation resources F.C. and F.J.A.-A.; writing-original draft preparation, F.C., R.O. and M.V.; supervision, Á.F.-B., C.V. and F.C.; project administration, F.J.A.-A. and F.C.; funding acquisition, F.J.A.-A. and F.C. All authors have read and agreed to the published version of the manuscript.

Funding: This research received no external funding.

Institutional Review Board Statement: The study was conducted according to the guidelines of the Declaration of Helsinki, and in accordance with the regulations of the relevant clinical research ethics approved by the National Ethics Committee of the Instituto Mexicano del Seguro Social, protocol code (Approval No: R-2020-3601-007 and R-2019-3601-004).

Informed Consent Statement: Not applicable.

Data Availability Statement: The data presented or additional data in this study are available on request from the corresponding author.

Acknowledgments: This work was submitted as part of the requirements for Rocio Ortega Gomez to obtain the Doctorado en Ciencias Biológicas y de la Salud (UAM-I). Rocio Ortega Gomez received financial support from CONACyt (593902). Fernando Calzada Bermejo received financial support for this project from FIS/IMSS (FIS/IMSS/PROT/PRIO/19/110; Project No. R-2020-3601-007 and R-2019-3601-004). The funders had no participation in the study's design, collection, and analysis of data, decision to publish, or preparation of the manuscript. ROG is grateful to MSc. Jesús Iván Solares Pascacio for the facilities and his help to obtain the plant material.

Conflicts of Interest: The authors declare no conflict of interest.

\section{References}

1. World Health Organization. Diabetes. Available online: https://www.who.int/news-room/fact-sheets/detail/diabetes (accessed on 23 November 2021).

2. American Diabetes Association. Diagnosis and Classification of Diabetes Mellitus. Available online: http://archives.diabetes. $\mathrm{org} /$ es/informacion-basica-de-la-diabetes/?loc=globalnav (accessed on 23 November 2021).

3. Guthrie, R.A.; Guthrie, D.A. Pathophysiology of Diabetes Mellitus. Crit. Care Nurs. Q. 2004, 27, 113-125. [CrossRef] [PubMed]

4. Maritin, A.; Sanders, R.; Watkins, J. Diabetes, oxidative stress, and antioxidants: A review. J. Biochem. Mol. Toxicol. 2003, 17, $24-38$. [CrossRef] [PubMed]

5. Wada, J.; Makino, H. Inflammation and the pathogenesis of diabetic nephropathy. Clin. Sci. 2013, 124, 139-152. [CrossRef] [PubMed]

6. Halimi, S. DPP-4 inhibitors and GLP-1 analogues: For whom? Which place for incretins in the management of type 2 diabetic patients? Diabetes Metab. 2008, 34, S91-S95. [CrossRef]

7. Lambeir, A.; Scharpé, S.; Meester, I. DPP4 inhibitors for diabetes-What next? Biochem. Pharmacol. 2008, 76, 1637-1643. [CrossRef] [PubMed]

8. Tasnuva, S.; Qamar, U.; Ghafoor, K.; Sahena, F.; Jahurul, M.; Rukshana, A.; Juliana, M.; Al-Juhaimi, F.; Jalifah, L.; Jalal, K.; et al. $\alpha$-glucosidase inhibitors isolated from Mimosa pudica L. Nat. Prod. Res. 2017, 33, 1495-1499. [CrossRef] [PubMed]

9. Furman, B. Acarbose. In Elsevier Strathclyde Institute of Pharmacy and biomedical Sciences, 1st ed.; Elsevier: Glasgow, UK, 2017; pp. 1-3. 
10. Aftab, S.; Surhesh, R.; Sherali, N.; Daniyal, M.; Tsouklidis, N. Sodium-glucose cotransporter-2 (SGLT-2) inhibitors: Benefits in diabetic with cardiovascular disease. Cureus 2020, 12, e10783. [CrossRef] [PubMed]

11. Alam, U.; Asghar, O.; Azmi, S.; Malik, R. General aspects of diabetes mellitus. Handb. Clin. Neurol. 2014, 126, $211-222$.

12. Valdés, M.; Calzada, F.; Mendieta-Wejebe, J. Structure-ativity relationship of acyclic terpenes in blood glucose levels: Potential $\alpha$-glucosidase and sodium glucose cotransporter (SGLT-1) inhibitors. Molecules 2019, 24, 4020. [CrossRef]

13. Valdés, M.; Calzada, F.; Mendieta-Wejebe, J.; Merlín-Lucas, V.; Velázquez, C.; Barbosa, E. Antihyperglycemic effects of Annona diversifolia Safford and its acyclic terpenoids: $\alpha$-glucosidase and selective SGLT1 inhibitors. Molecules 2020, 25, 3361. [CrossRef]

14. De Melo, E.B.; da Silveira, A.G.; Carvalho, I. $\alpha$ - and $\beta$-glucosidase inhibitors: Chemical structure and biological activity. Tetrahedron 2006, 62, 10277-10302. [CrossRef]

15. Castrejón, V.; Carbó, R.; Martínez, M. Mecanismos moleculares que intervienen en el transporte de la glucosa. Rev. Ed. Bioq. 2007, 368, 85-97.

16. Asante, D.; Effah-Yeboah, E.; Barnes, P.; Abban, H.A.; Ameyaw, E.O.; Boampong, J.N.; Ofori, E.G.; Dadzie, J. Antidiabetic effect of young and old ethanolic leaf extracts of Vernonia amygdalina: A comparative study. J. Diabetes Res. 2016, 2016, 8252741. [CrossRef]

17. Salinas-Arellano, E.; Pérez-Vásquez, A.; Rivero-Cruz, I.; Torres-Colin, R.; González-Andrade, M.; Rangel-Grimaldo, M.; Mata, R. Flavonoids and terpenoids with PTP-1B inhibitory properties from the infusion of Salvia amarissima Ortega. Molecules 2020, 25, 3530. [CrossRef] [PubMed]

18. IDF. Diabetes Atlas, 9th ed.; International Diabetes Federation: Brussels, Belgium, 2019. Available online: https://www. diabetesatlas.org/ (accessed on 29 November 2021).

19. Brindis, F.; Rodríguez, R.; Bye, R.; González-Andrade, M.; Mata, R. (Z)-3-butylidenephthalide from Ligusticum porteri, an $\alpha$-glucosidase inhibitor. J. Nat. Prod. 2011, 74, 314-320. [CrossRef]

20. Solares-Pascasio, J.I.; Ceballos, G.; Calzada, F.; Barbosa, E.; Velazquez, C. Antihyperglycemic and lipid profile effects of Salvia amarissima Ortega on Streptozocin-Induced Type 2 diabetic mice. Molecule 2021, 26, 947. [CrossRef]

21. Zarei, A.; Vaezi, G.; Malekirad, A.A.; Abdollahi, M. Hypoglycemic and hypolipidemic activities of Salvia hydrangea in streptozotocin-induced diabetes in rats. Iran. J. Basic Med. Sci. 2015, 18, 417-422.

22. Sairafianpour, M.; Bahreininejad, B.; Witt, M.; Ziegler, H.L.; Jaroszewski, J.W.; Stærk, D. Terpenoids of Salvia hydrangea: Two new, rearranged 20-norabietanes and the effect of oleanolic acid on erythrocyte membranes. Planta Med. 2003, 69, 846-850.

23. Flores-Bocanegra, L.; González-Andrade, M.; Bye, R.; Linares, E.; Mata, R. $\alpha$-glucosidase inhibitors from Salvia circinata. J. Nat. Prod. 2017, 80, 1584-1593. [CrossRef]

24. Bahadori, M.B.; Salehi, P.; Sonboli, A. Comparative study of the essential oil composition of Salvia urmiensis and its enzyme inhibitory activities linked to diabetes mellitus and Alzheimer's disease. Int. J. Food Prop. 2017, 20, 2974-2981. [CrossRef]

25. Bautista, E.; Fragoso-Serrano, M.; Ortiz-Pastrana, N.; Toscano, R.; Ortega, A. Structural elucidation and evaluation of multidrug-resistance modulatory capability of amarissinins A-C, diterpenes derived from Salvia amarissima. Fitoterapia 2016, 114, 1-6. [CrossRef] [PubMed]

26. Bautista, E.; Fragoso-Serrano, M.; Toscano, R.; García-Peña, M.; Ortega, A. Teotihuacanin, a diterpene with an unusual spiro-10/6 system from Salvia amarissima with potent modulatory activity of multidrug resistance in cancer cells. Org. Lett. 2015, 17, 3280-3282. [CrossRef] [PubMed]

27. Esquivel, B.; Esquivel, O.; Cárdenas, J.; Adela Sánchez, A.; Ramamoorthy, T.P.; Alfredo Toscano, R.; Rodríguez-Hahn, L. Clerodane and seco-clerodane diterpenoids from Salvia reptans. Phytochemistry 1991, 30, 2335-2338. [CrossRef]

28. Aydoğmuş, Z.; Yeşilyurt, V.; Topcu, G. Constituents of Salvia microphylla. Nat. Prod. Res. 2006, 20, 775-781. [CrossRef]

29. Maldonado, E.; Cárdenas, J.; Bojórquez, H.; Escamilla, E.M.; Ortega, A. Amarisolide, a neo-clerodane diterpene glycoside from Salvia amarissima. Phytochemistry 1996, 42, 1105-1108. [CrossRef]

30. Jaeger, R.; Cuny, E. Terpenoids with special pharmacological significance: A review. Nat. Prod. Commun. 2016, 11, 1373-1390. [CrossRef]

31. Rzedowski, J.; de Rzedowski, G. Tres especies mexicanas de Lobelia (Campanulaceae, Lobelioideae), una redescubierta y dos nuevas. Acta Bot. Mex. 2001, 55, 29-38. [CrossRef]

32. Ríos, J.V.; García, F.E. Catálogo de malezas de México. Consejo Nacional Consultivo Fitosanitario; Universidad Nacional Autónoma de México: Mexico City, Mexico, 1998.

33. Ortega, A.; Bautista, E.; Maldonado, E. Polystachyne F, a 5,10-seco-neoclerodane from Salvia polystachya. Chem. Pharm. Bull. 2006, 54, 1338-1339. [CrossRef]

34. Bushway, A.; Belyea, R.; Bushway, J. Chia seed as a source of oil, polysaccharide. Food Sci. 1981, 46, 1349-1350. [CrossRef]

35. Calzada, F.; Yepez-Mulia, L.; Tapia-Contreras, A.; Bautista, E.; Maldonado, E.; Ortega, A. Evaluation of the antiprotozoal activity of neo-clerodane type diterpenes from Salvia polystachya against Entamoeba histolytica and Giardia lamblia. Phyther. Res. 2010, 24, 662-665.

36. Bautista, E.; Ortiz-Pastrana, N.; Pastor-Palacios, G.; Montoya-Contreras, A.; Toscano, R.A.; Morales-Jiménez, J.; Salazar-Olivo, L.A.; Ortega, A. Neo-clerodane diterpenoids from Salvia polystachya stimulate the expression of extracellular matrix components in human dermal fibroblasts. J. Nat. Prod. 2017, 80, 3003-3009. [CrossRef]

37. OCDE. Guideline for Testing if Chemicals. Acute Oral Toxicity-Acute Toxic Class Method. 2001; pp. 1-14. Available online: https:/ /ntp.niehs.nih.gov/Iccvam/suppdocs/feddocs/oecd/oecd_gl423.pdf (accessed on 26 November 2021).

38. Skudelski, T. The mechanism of alloxan and streptozotocin action in B cells of the rat pancreas. Physiol Res. 2001, 50, 537-546.

39. Diab, H.; Fares, M.; Abdei-Valugerdi, M.; Kumagai-Baresch, M.; Holgersson, J.; Hassan, M. Immunotoxicological effects of streptozotocin and alloxan in vitro and in vivo studies. Imminol. Lett. 2015, 163, 193-198. [CrossRef] [PubMed] 
40. Chatuphonprasert, W.; Lao-Ong, T.; Jarukamjorn, K. Improvement of superoxide dismutase and catalase in streptozotocin-nicotinamideinduced type 2-diabetes in mice by berberine and glibenclamide. Pharm. Biol. 2014, 52, 419-427. [CrossRef] [PubMed]

41. Ovalle-Magallanes, B.; Medina-Campos, O.N.; Pedraza-Chaverri, J.; Mata, R. Hypoglycemic and antihyperglycemic effects of phytopreparations and limonoids from Swietenia humilis. Phytochemistry 2015, 110, 111-119. [CrossRef] [PubMed]

42. Calabrese, E.J.; Blain, R.B. Hormesis and plant biology. Environ. Pollut. 2009, 157, 42-48. [CrossRef] [PubMed]

43. Jang, S.M.; Yee, S.T.; Choi, J.; Choi, M.S.; Do, G.M.; Jeon, S.M.; Yeo, J.; Kim, M.J.; Seo, K.-I.; Lee, M.-K. Ursolic acid enhances the cellular immune system and pancreatic $\beta$-cell function in streptozotocin-induced diabetic mice fed a high-fat diet. Int. Immunopharmacol. 2009, 9, 113-119. [CrossRef] [PubMed]

44. Castro, A.J.G.; Frederico, M.J.S.; Cazarolli, L.H.; Mendes, C.P.; Bretanha, L.C.; Schmidt, É.C.; Bouzon, Z.L.; de Medeiros, V.A.P.; da Fonte, C.R.; Pizzolatti, M.G.; et al. The mechanism of action of ursolic acid as insulin secretagogue and insulinomimetic is mediated by cross-talk between calcium and kinases to regulate glucose balance. Biochim. et Biophys. Acta (BBA) Gen. Subj. 2015, 1850, 51-61. [CrossRef] [PubMed]

45. Jhong, C.H.; Riyaphan, J.; Lin, S.H.; Chia, Y.C.; Weng, C.F. Screening alpha-glucosidase and alpha-amylase inhibitors from natural compounds by molecular docking in silico. BioFactors 2015, 41, 242-251. [CrossRef]

46. Kuroda, S.; Kobashi, Y.; Oi, T.; Amada, H.; Okumura-Kitajima, L.; Io, F.; Yamamto, K.; Kakinuma, H. Discovery of a potent, low-absorbable sodium-dependent glucose cotransporter 1 (SGLT1) inhibitor (TP0438836) for the treatment of type 2 diabetes. Bioorganic Med. Chem. Lett. 2018, 28, 3534-3539. [CrossRef] [PubMed]

47. Röder, P.V.; Geillinger, K.E.; Zietek, T.S.; Thorens, B.; Koepsell, H.; Daniel, H. The role of SGLT1 and GLUT2 in intestinal glucose transport and sensing. PLoS ONE 2014, 9, 20-22. [CrossRef] [PubMed]

48. Yoshikawa, T.; Inoue, R.; Matsumoto, M.; Yajima, T.; Ushida, K.; Iwanaga, T. Comparative expression of hexose transporters (SGLT1, GLUT1, GLUT2, and GLUT5) throughout the mouse gastrointestinal tract. Histochem. Cell Biol. 2011, 135, 183-194. [CrossRef] [PubMed]

49. Gorboulev, V.; Schurmann, A.; Vallon, V.; Kipp, H.; Jaschke, A.; Klessen, A.; Scherneck, S.; Rieg, T.; Cunard, M.; Srinivasan, A.; et al. $\mathrm{Na}(+)$-D-glucose cotransporter SGLT1 is pivotal for intestinal glucose absorption and glucose-dependent incretin secretion. Diabetes 2012, 61, 187-196. [CrossRef] [PubMed]

50. Dirir, A.M.; Daou, M.; Yousef, A.F.; Yousef, L.F. A review of alpha-glucosidase inhibitors from plants as potential candidates for the treatment of type-2 diabetes. Phytochem. Rev. 2021, 1-31. [CrossRef]

51. Ding, H.; Hu, X.; Xu, X.; Zhang, G.; Gong, D. Inhibitory mechanism of two allosteric inhibitors, oleanolic acid and ursolic acid on

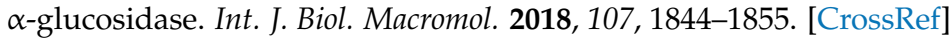

52. Jäger, S.; Trojan, H.; Kopp, T.; Laszczyk, M.N.; Scheffler, A. Pentacyclic triterpene distribution in various plants-Rich sources for a new group of multi-potent plant extracts. Molecules 2009, 14, 2016-2031. [CrossRef]

53. Poongunran, J.; Perera, H.K.I.; Jayasinghe, L.; Fernando, I.T.; Sivakanesan, R.; Araya, H.; Fujimoto, Y. Bioassay-guided fractionation and identification of $\alpha$-amylase inhibitors from Syzygium cumini leaves. Pharm. Biol. 2017, 55, 206-211. [CrossRef]

54. Castellano, J.M.; Guinda, A.; Delgado, T.; Rada, M.; Cayuela, J.A. Biochemical basis of the antidiabetic activity of oleanolic acid and related pentacyclic triterpenes. Diabetes 2013, 62, 1791-1799. [CrossRef]

55. Prasad, S.; Tyagi, A.K.; Aggarwal, B.B. Detection of inflammatory biomarkers in Saliva and urine: Potential in diagnosis, prevention, and treatment for chronic diseases. Exp. Biol. Med. 2016, 241, 783-799. [CrossRef]

56. Šulniūtè, V.; Pukalskas, A.; Venskutonis, P.R. Phytochemical composition of fractions isolated from ten Salvia species by supercritical carbon dioxide and pressurized liquid extraction methods. Food Chem. 2017, 224, 37-47. [CrossRef]

57. Topçu, G. Bioactive triterpenoids from Salvia species. J. Nat. Prod. 2006, 69, 482-487. [CrossRef] [PubMed]

58. Abd, A.R.; Rathi, D.G. Bioactive components of Salvia and their potential antidiabetic properties: A review. Molecules 2021, $26,3042$.

59. Mahdizadeh, R.; Moein, S.; Soltani, N.; Malekzadeh, K.; Mahmoodreza, M. Study the molecular mechanism of Salvia species in prevention of diabetes. Int. J. Pharm. Sci. Res. 2018, 9, 4512-4521.

60. Khan, T.; Zahid, M.; Asim, M.; Iqbal, Z.; Choudhary, M.I.; Ahmad, V.U. Pharmacological activities of crude acetone extract and purified constituents of Salvia moorcraftiana Wall. Phytomedicine 2002, 9, 749-752. [CrossRef] [PubMed]

61. Nickavar, B.; Abolhasani, L. Bioactivity-guided separation of an $\alpha$-amylase inhibitor flavonoid from Salvia virgata. Iran. J. Pharm. Res. 2013, 12, 57-61.

62. Guzmán-Ávila, R.; Flores-Morales, V.; Paoli, P.; Camici, G.; Ramírez-Espinosa, J.J.; Cerón-Romero, L.; Navarrete-Vázquez, G.; Hidalgo-Figueroa, S.; Yolanda Rios, M.; Villalobos-Molina, R.; et al. Ursolic acid derivatives as potential antidiabetic agents: In vitro, in vivo, and in silico studies. Drug. Dev. Res. 2018, 79, 70-80. [CrossRef]

63. Norma Oficial Mexicana. NOM-062-ZOO-1999: Especificaciones Técnicas Para la Producción, Cuidado y Uso de los Animals de Laboratorio. 1999. Available online: https://www.fmvz.unam.mx/fmvz/principal/archivos/062ZOO.PDF (accessed on 25 November 2021).

64. Porwal, M.; Khan, N.A.; Maheshwari, K.K. Evaluation of acute and subacute oral toxicity induced by ethanolic extract of Marsdenia tenacissima leaves in experimental rats. Sci. Pha. 2017, 85, 29. [CrossRef]

65. Hanwell, M.; Curtis, D.; Lonie, D.; Vandermeersch, T.; Zurek, E.; Hutchison, G. Avogadro: An advanced semantic chemical editor visualization, and analysis platform. J. Cheminform. 2012, 4, 17. [CrossRef]

66. Morris, G.; Lindstrom, W.; Sanner, M.; Belew, R.; Goodshell, D.; Olson, A. Autodock4 and AutodockTools4: Automated docking with selective receptor flexibility. J. Comput. Chem. 2009, 30, 2785-2791. [CrossRef] 